\title{
Statistical properties of aerosol-cloud-precipitation interactions in South America
}

\author{
T. A. Jones ${ }^{1}$ and S. A. Christopher ${ }^{1,2}$ \\ ${ }^{1}$ Earth System Science Center, UAHuntsville, Huntsville, AL, USA \\ ${ }^{2}$ Department of Atmospheric Science, UAHuntsville, Huntsville, AL, USA
}

Received: 13 May 2009 - Published in Atmos. Chem. Phys. Discuss.: 12 October 2009

Revised: 26 February 2010 - Accepted: 2 March 2010 - Published: 5 March 2010

\begin{abstract}
Given the complex interaction between aerosol, cloud, and atmospheric properties, it is difficult to extract their individual effects to observed rainfall amount. This research uses principle component analysis (PCA) that combines Moderate Resolution Imaging Spectroradiometer (MODIS) aerosol and cloud products, NCEP Reanalysis atmospheric products, and rainrate estimates from the Tropical Rainfall Measuring Mission (TRMM) precipitation radar (PR) to assess if aerosols affect warm rain processes. Data collected during September 2006 over the Amazon basin in South America during the biomass-burning season are used. The goal of this research is to combine these observations into a smaller number of variables through PCA with each new variable having a unique physical interpretation. In particular, we are concerned with PC variables whose weightings include aerosol optical thickness (AOT), as these may be an indicator of aerosol indirect effects. If they are indeed occurring, then PC values that include AOT should change as a function of rainrate.

To emphasize the advantage of PCA, changes in aerosol, cloud, and atmospheric observations are compared to rainrate. Comparing no-rain, rain, and heavy rain only $\left(>5 \mathrm{~mm} \mathrm{~h}^{-1}\right)$ samples, we find that cloud thicknesses, humidity, and upward motion are all greater during rain and heavy rain conditions. However, no statistically significant difference in AOT exists between each sample, indicating that atmospheric conditions are more important to rainfall than aerosol concentrations as expected. If aerosols are affecting warm process clouds, it would be expected that stratiform precipitation would decrease as a function increasing aerosol concentration through either Twomey and/or semidirect effects. PCA extracts the latter signal in a variable labeled PC2, which explains $15 \%$ of the total variance and is
\end{abstract}

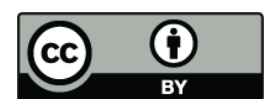

Correspondence to: T. A. Jones (tjones@nsstc.uah.edu) second in importance the variable (PC1) containing the broad atmospheric conditions. PC2 contains weightings showing that AOT is inversely proportional to low-level humidity and cloud optical thickness. Increasing AOT is also positively correlated with increasing low-level instability due to aerosol absorption. The nature of these weightings is strongly suggestive that PC2 is an indicator of the semi-direct effect with larger values associated with lower rainfall rates. PC weightings consistent with the Twomey effect (an anti-correlation between AOT and cloud droplet effective radius) are only present in higher order PC variables that explain less than $1 \%$ of the total variance, and do not vary significantly as a function of rainrate. If the Twomey effect is occurring, it is highly non-linear and/or being overshadowed by other processes. Using the raw variables alone, these determinations could not be made; thus, we are able to show the advantage of using advanced statistical techniques such as PCA for analysis of aerosols impacts on precipitation in South America.

\section{Introduction}

Modeling and observational studies indicate that cloud properties in the vicinity of high aerosol concentrations can be significantly altered (e.g. Ackerman et al., 2000; Penner et al., 2004; Koren et al., 2005; Rosenfeld et al., 2006). Certain types of aerosols (e.g. sulfates) are water soluble and act as excellent $\mathrm{CCN}$ for cloud liquid water droplets resulting in an increase in available $\mathrm{CCN}$ for cloud formation. If atmospheric conditions such as temperature, water content, and vertical motion are held constant, increasing $\mathrm{CCN}$ will result in smaller water droplets compared to a less polluted region, increasing cloud albedo and reflecting more solar radiation back into space. This is known as the first indirect, or the Twomey effect (Twomey, 1977; Kaufman and Fraser, 1997; Feingold, 2003). For example, Kaufman et al. (2005) observed that liquid water drop effective radius $\left(R_{\mathrm{c}}\right)$ decreased

Published by Copernicus Publications on behalf of the European Geosciences Union. 
by $32 \%$ when AOT increased from 0.03 to 0.43 over oceanic regions between $5^{\circ} \mathrm{N}$ and $-20^{\circ} \mathrm{S}$. These changes were attributed to an increase in smoke aerosols from the Amazon (and central Africa) owing to an increase in biomass burning. The increase in albedo due to smaller drop sizes produced a cooling at the top of the atmosphere of $-1.5 \mathrm{~W} \mathrm{~m}^{-2}$. However, this relationship does not always occur as Peng et al. (2002) observed a positive correlation between AOT and $R_{\mathrm{c}}$ for highly polluted regions in the Arabian Sea.

A decrease in cloud droplet size has the additional effect of delaying the onset of collision and coalescence in warm clouds, reducing precipitation efficiency and increasing the lifespan and the areal coverage of the cloud, which has been labeled as the second indirect effect (Albrecht, 1989; Quaas et al., 2004). Reducing precipitation efficiency also acts to increase water loading, leading to an increase in cloud liquid water path (LWP) and a corresponding increase in cloud thickness, complicating the identification of the Twomey effect in observations (Reid et al., 1998; Schwartz et al., 2002). Both the first and second indirect effects act to cool the atmosphere, partially offsetting warming due to greenhouse gases (Lohmann and Feichter, 2005). However, absorbing aerosols such as soot from biomass burning can suppress cloud formation by warming the atmosphere, increasing evaporation of water droplets and also increasing atmospheric stability, which is known as the semi-direct effect (Hanson et al., 1997; Ackerman et al., 2000; Johnson et al., 2004).

Given the complex interaction between atmospheric conditions, aerosol concentrations, and cloud properties, extracting aerosol effects on cloud properties and rainfall from an observational perspective is challenging under the best of circumstances (e.g. Brenguier et al., 2003; Quaas et al., 2004, 2008). Both the first and second aerosol indirect effects and the semi-direct effect described above should lead to a reduction in precipitation compared to less polluted regions (Ramanathan et al., 2001). While the relationship between aerosols and cloud properties has been well established, the effect on precipitation has only been examined from an observational perspective on a limited basis (e.g. Rosenfeld et al., 2006; Martins et al., 2008). Using numerical modeling output, Martins et al. (2008) observed that increases in aerosol concentration generally reduced rainrate values associated with warm rain processes $\left(<5 \mathrm{~mm} \mathrm{~h}^{-1}\right)$. Numerical modeling studies by Teller and Levin (2006) and Khain et al. (2005) have also noted that less precipitation occurred during high levels of pollution during warm cloud processes.

However, Andreae et al. (2004), Lin et al. (2006), and Martins et al. (2008) have also observed an increase in precipitation associated with an increase in pollution, at least for high rainrate examples $\left(>5 \mathrm{~mm} \mathrm{~h}^{-1}\right)$. Since biomass burning aerosols delay the onset of precipitation through slower droplet growth, the drag on updrafts produced by raindrops is reduced, allowing a greater number of smaller droplets to reach higher altitudes, causing additional latent heat release when they freeze (Martins et al., 2008). The resulting increase in buoyancy in turn creates an environment for favorable for convective precipitation, which at least for localized regions, can more than offset the decrease warm process precipitation due to pollution. Since this effect impacts the likelihood of convective rainfall, it is labeled the "convective effect" for the remainder of this work, While modeling and observational evidence for this occurring exists (Khain et al., 2005; Lin et al., 2006), which effect is dominant over large regions remains unclear.

This research focuses on the warm cloud component of these processes where we hypothesize that if aerosol indirect (or semi-direct) effects are indeed occurring, the resulting decrease in collision and coalescence and/or the increase in atmospheric stability should result in a decrease in stratiform precipitation amount compared to the same environment in more pristine conditions. The combination of these various processes is hereafter referred to as "aerosol effects". TRMM-PR separates precipitation into stratiform vs. convective elements using the observed radar reflectivity characteristics allowing for an assessment on the importance of precipitation type relative to aerosol indirect effects. Extracting the physical signals from these data is a difficult task given the uncertainties in precipitation measurements and the influence of many other atmospheric conditions to rainfall, requiring the implementation of additional analysis techniques.

To accomplish this task, this research combines aerosol and cloud data from the MODIS with atmospheric conditions provided by NCEP Reanalysis and rainrate data derived from the precipitation radar onboard the TRMM satellite. Available parameters include aerosol optical thickness, cloud optical thickness, liquid water droplet effective radius (from MODIS), wind speed and direction, humidity, temperature, vertical motion (from NCEP), and finally rainrate and rain-type from TRMM-PR. Combining these parameters is a crucial step for unraveling these effects, but also introduces significant challenges. Given the high correlation between many of these parameters, deriving a statistically significant relationship between parameters such as AOT and rainrate alone is challenging. Multiple linear regression techniques using aerosol, cloud, and atmospheric properties have been used to examine the presence of aerosol indirect effects (e.g. Kaufman et al., 2005). For example, Kaufman et al. (2005) estimated that the effect of aerosols and independent meteorological observations relative to cloud cover to be roughly equal, but that changes in aerosol and cloud cover due to the same atmospheric conditions occurred only $30 \%$ of the time. Thus, $70 \%$ of the change in cloud cover in the Atlantic was attributed to dust aerosols.

The high correlation between various parameters makes physical interpretation if individual variables in the regression equation difficult, limiting their usefulness. While it is possible to combine various atmospheric parameters into more complex variables such as the Cloud Work Function (Lin et al., 2006), related cloud and aerosol parameters remain left out. To remedy this situation, we apply PCA to the 

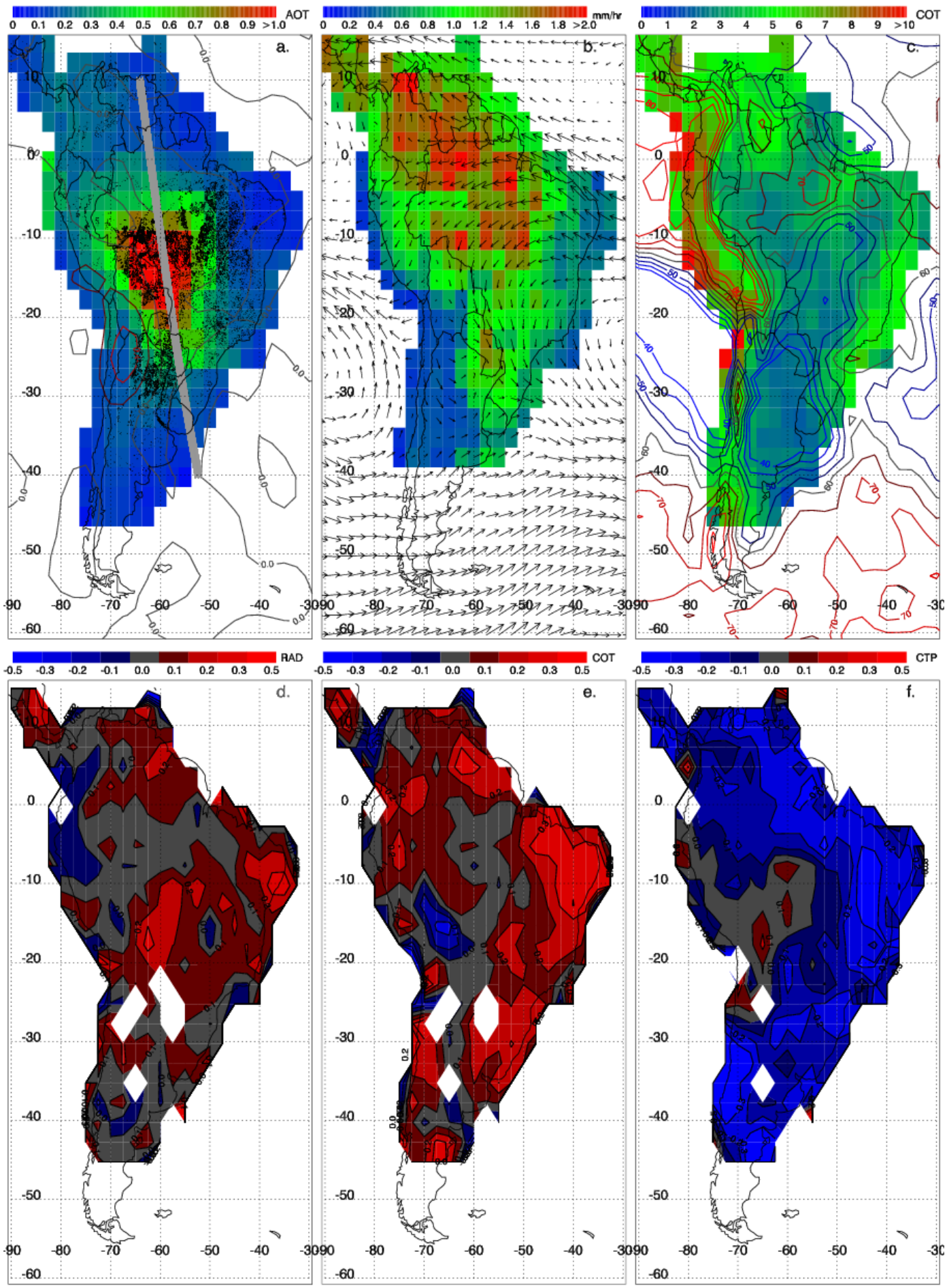

Fig. 1. Monthly averaged AOT (a), TRMM rainrate in $\mathrm{mm} \mathrm{h}^{-1}$ (b), and COT (c) over South America for September 2006. Overlaid on AOT are MODIS derived fire locations from the MOD14 product during the same month. NCEP Reanalysis wind vectors at $850 \mathrm{hPa}$ are overlaid on rainrate, and relative humidity contours are overlaid on COT. Gray line in panel (a) represents the location of a CALIPSO overpass on 22 September 2006 at approximately 18:00 UTC. Panels (d), (e), and (f) represent the correlation coefficients between AOT and $R_{\mathrm{c}}(\mathrm{d})$, COT (e) and CTP (f) for each $2.5^{\circ}$ grid cell. Red values indicate a positive correlation while blue values indicate a negative correlation. 
combined data set to reduce the overall number of parameters to something more manageable by grouping linearly correlated observations into a fewer number of variables in PC space (Wilks, 2006). In essence, PCA combines information from highly correlated observations such as vertical velocity and cloud top pressure into a single variable. These new variables each have a unique meaning and are generally uncorrelated with one another. Some represent important physical properties relating to the atmosphere and clouds, while others may represent non-physically significant observations and random noise.

This research is focused on the South American continent where large aerosol concentrations produced from biomass burning, especially during the month of September as indicated by the large number of fires and smoke plumes from MODIS (Fig. 1a). In particular, biomass burning in central South America produces AOT $>1.0$ over a rather large region (Fig. 1a). This period corresponds to the "dry season" in the Amazon, but significant ( $>100 \mathrm{~mm}$ per month) precipitation is still occurring over this region (Fig. 1b) (Williams et al., 2002). The period of highest AOT corresponds with the lowest overall precipitation amounts that at first glance would seem to be an indicator of warm process aerosol indirect effects. However, the changing atmospheric conditions from season to season make extracting this effect difficult without determining the interrelationships between atmospheric conditions, clouds, and aerosols. Koren et al. (2008) compared MODIS AOT and cloud property retrievals over the Amazon during the dry season and observed that for $\mathrm{AOT}>0.4$, that increasing aerosol concentrations acted to decrease cloud cover due to an increase in atmospheric stability in the aerosol layer. Using aircraft measurements, Reid et al. (1999) did not observe a significant relationship between AOT and $R_{\mathrm{c}}$ while Kaufman and Fraser (1997) did find a significant anti-correlation between AOT and $R_{\mathrm{c}}$ for this region using AVHRR data. The aerosol indirect effect observed by Kaufman and Fraser (1997) was much smaller than that expected from model predictions. The presence of semi-direct effects from soot and other absorbing aerosols could explain this shortfall. If aerosol indirect effects and/or semi-direct effects are occurring, they should manifest themselves in some combination of the aerosol, cloud, and atmospheric observations present at any one time. This combination may represent both linear and non-linear interactions between variables. The analysis method used by this research will extract the quasi-linear combinations, but not-necessarily the non-linear combinations that certainly do exist. To examine whether or not any linear relationships are present over this region, data from the month of September 2006 was selected since significant aerosol, cloud, and precipitation concentrations are collocated over a large area of South America.

The goal of this research is to explore the hypothesis that aerosol indirect and/or semi-direct effects, as they relate to the occurrence and intensity of precipitation, can be extracted from the combined aerosol, cloud, and atmospheric condi- tions database to a statistically significant level. Two methods will be employed in order to test this hypothesis. First, the basic descriptive statistics (mean and standard deviation) of the rain vs. no rain samples are compared to determine whether or not statistically significant differences exist between the sample means. A similar test will be conducted using the new variables produced using PCA. Second, the new PC variables that prove statistically significant at discriminating between rain and no-rain samples are compared with rainrate to determine if a statistically significant relationship exists here too. If aerosol indirect or semi-direct effects are affecting rainfall, then variables whose weightings are indicative of indirect effects (e.g. AOT and cloud droplet effective radius inversely weighed), should also show a significant relationship to rainrate. While regression functions between rainrate and PC variables are created as part of this process, we stress that these functions should not be thought of as any sort of prognostic models. The goal of this research is to show whether or not a statistically significant relationship exists, not how to accurately model it.

\section{Data}

\subsection{Cloud properties}

The Clouds and Earth's Radiant Energy System (CERES) Single Scanner Footprint (SSF) FM1, Edition 2F data between for September from the Terra and FM3, Edition 2C Aqua satellites (in a sun-synchronous orbit with an equatorcrossing local time of about 10:30 a.m. and 1:30 p.m., respectively) are collected for the South American region (Fig. 1). The CERES-SSF product combines the radiative fluxes retrieved from the CERES instrument with aerosol properties from the MOD04 (Collection 5) product (Remer et al., 2006) and cloud (Minnis et al., 2003) properties retrieved from MODIS. The CERES-SSF footprint resolution is $\sim 20 \mathrm{~km}$ at nadir with a near daily global coverage. Derived cloud properties include cloud liquid water path (LWP), water cloud effective droplet radii $\left(R_{\mathrm{c}}\right)$, cloud optical thickness (COT), and cloud top pressure (CTP) (Minnis et al., 2003). MODIS is capable of providing cloud characteristics at two different levels, one nearer to the surface, the other (if it exists) higher in the atmosphere. The second cloud layer is retrieved for less than 5\% of all cloud observations. Since the second cloud layer is comparatively rare and since we choose to only investigate aerosol effects on low-level liquid water clouds, data associated with the upper cloud layers are removed. The only constraints placed on the data (outside normal quality control flags) is that MODIS cloud data are only used for pixels over land surfaces and when the MODIS cloud phase parameter indicates that the cloud in question is at least $99 \%$ comprised of liquid water droplets. A quantitative assessment of the effects of aerosols on ice clouds are beyond the scope of this study (e.g. Demott et al., 2004). Compared to 
the cloud retrieval in the MOD06 product (Platnick et al., 2003), CERES-SSF generally produces smaller $R_{\mathrm{c}}$ and COT values, though the overall patterns are generally similar with cloud amounts differing less than 10\% (Minnis et al., 2003).

Platnick et al. (2003) provide a review of the various error sources in the retrieval process including calibration, assumptions in atmospheric and surface properties, ambiguous solutions for optically thin clouds calibration, vertical heterogeneity of clouds and cirrus contamination. One significant uncertainty related to this research is that associated with optically thin clouds (e.g. Nakajima and King, 1990). Under these circumstances, the relationship between retrieved COT and cloud droplet effective radius may be ambiguous. However, we cannot ignore optically thin clouds as part of this research as they contribute a large portion of the total cloud cover (Turner et al., 2007; Jones and Christopher, 2008). As a result, data from both thin and thick clouds are retained for the following analysis.

\subsection{Aerosol properties}

MODIS products are derived from cloud-free $500 \mathrm{~m}$ resolution data $(20 \times 20$ pixels $)$ and aggregated to $10 \mathrm{~km}$ footprint used by the Collection 5 MODIS level 2 aerosol product (MOD04). At least 10 pixels must remain (2.5\%) after cloud masking and other quality control procedures for an AOT retrieval to be made. The nature of the cloud masking algorithm used by MODIS is such that it tends to classify very thick aerosol layers (i.e. dust over the North Atlantic) as clouds and not aerosols (Remer et al., 2006). As a result, total AOT may be somewhat underestimated. If a retrieval is made, the $10 \mathrm{~km}$ aerosol products are convolved within the CERES $20 \mathrm{~km}$ (nadir) field of view (FOV) using a point spread weighting function (Loeb et al., 2005). Both "average" and "best" AOT retrievals are included in the CERES-SSF AOT. The reported uncertainty of the MODIS AOT product over land is $\pm 0.05 \pm 0.15 \tau$ (Remer et al., 2006). Collocated CERES-SSF data are used rather than the original level 2 MODIS aerosol and cloud products since future studies will examine the radiative impact of clouds and aerosols.

While the MODIS algorithm uses strict cloud-clearing thresholds when calculating AOT, some cloud contamination does remain (Remer et al., 2006; Zhang and Reid, 2006; Yuan et al., 2008). Some aerosols species, such as sea salt and sulfate, are hygroscopic and will grow in size in the high humidity environments present in the vicinity of clouds, producing higher visible and near infrared reflectances near clouds for the same aerosol concentrations (Feingold et al., 2003; Jeong et al., 2007). Humidified aerosols are still aerosols and the increase in scattering is appropriately part of AOT; however, the increase in AOT as a function of humidity complicates the interpretation of the relationship between aerosol and cloud properties (Koren et al., 2007). The magnitude of the increase in AOT in the vicinity of clouds compared to cloud free regions has been estimated to be $13 \%$ and $11 \%$ for visible wavelengths when comparing against AERONET and MODIS data respectively (Koren et al., 2007). If the increase in AOT is a result of an increase in aerosol size, then parameters such Angstrom exponent and FMF should also be sensitive to cloud coverage (Koren et al., 2007; Redemann et al., 2009). Koren et al. (2007) observed lower Angstrom exponent values near clouds, and attributed these values to larger, humidified aerosols and/or small cloud droplets being improperly identified as aerosols.

The increase in AOT due to aerosols that have been activated into undetected cloud droplets represents another significant uncertainty. Since they are not being classified as clouds, backscattered radiation is sometimes attributed to aerosols, in this case falsely increasing AOT. Koren et al. (2007) suggest that both humidification and non-detected clouds are causing an increase in AOT near clouds, increasing the difficulty of determining what effects aerosols have on cloud properties. Since aerosols and clouds cannot sampled simultaneously in an independent manner, studies using satellite observations must make an assumption that aerosol properties near clouds are similar enough to aerosol properties within clouds to compute useful relationships between aerosol and cloud properties. Thus, differences between aerosol and cloud properties must change by at least 15-20\% to be considered significant outside these effects. Otherwise, no conclusions can be drawn.

One other important consideration is that spurious scattering from nearby clouds may also lead to a high bias in AOT retrievals, which is known as the 3-D effect (Wen et al., 2006; Mauger and Norris, 2007; Marshak et al., 2008). However, Wen et al. (2006) observed that this phenomena only occurs on a spatial scale of a few kilometers. Since MODIS derived AOT at $10 \mathrm{~km}$ (and we use AOT data that has been remapped to a $20 \mathrm{~km}$ resolution), this effect will not be resolvable in the MODIS data used here and should not significantly impact the interpretation of the results (Koren et al., 2007). The primary reason this phenomenon is not a major impact lies in the manner in which MODIS AOT is retrieved. Before deriving a $10 \mathrm{~km}$ AOT pixels for cloud-free data, the $25 \%$ highest and lowest reflectivity pixels at $500 \mathrm{~m}$ within a $10 \times 10 \mathrm{~km}$ area are removed (Remer et al., 2006). Since the number of anomalously high reflectance $500 \mathrm{~m}$ pixels due to this effects is likely small compared to the total sample, removing the highest reflectivity values would remove much of this effect in the final AOT product.

\subsection{NCEP data}

Daily wind speed and direction, relative humidity, temperature, and vertical velocity between 1000 and $700 \mathrm{hPa}$ levels are obtained from National Center for Environmental Prediction (NCEP) Reanalysis data. Since we are primarily interested in warm process clouds, we focus on atmospheric conditions below the freezing level. The NCEP Reanalysis contains global meteorological conditions with a $2.5^{\circ}$ horizontal 
resolution and a 17 level vertical resolution at $6 \mathrm{~h}$ time intervals (Kalnay et al., 1996). This research uses the raw values from the 925,850 , and $700 \mathrm{hPa}$ levels as well as the temperature difference between the surface $(1000 \mathrm{hPa})$ and $700 \mathrm{hPa}$ to provide an estimate of atmospheric lapse rate and lowlevel stability. Negative values indicate temperature decreasing with height (more unstable) with positive values indicating temperature increasing with height (stable). Including potential temperature was considered, but tests showed that it did not add much independent information when included with the raw temperature and humidity parameters. Vertical velocity is reported in pressure coordinates $\left(\mathrm{Pa} \mathrm{s}^{-1}\right)$; thus, positive values indicate sinking air while negative values indicate rising air. As in previous aerosol indirect effect studies such as Jones and Christopher (2008), the focus is on changes in NCEP variables not necessarily their absolute magnitudes owing to various uncertainties present in the NCEP product.

\subsection{TRMM-PR rainrate data}

The TRMM satellite was launched in 1997 into a unique orbit that maximizes observations of the tropical regions in a $\pm 40^{\circ}$ latitude band (Kummerow et al., 2000). Both a passive microwave sensor (TMI) and an active microwave radar (PR) are located onboard the satellite. For this research, data from the PR are used (Iguchi et al., 2000). The PR derives radar reflectivity at $13.8 \mathrm{Ghz}$ with a $250 \mathrm{~m}$ vertical and $4 \mathrm{~km}$ horizontal resolution over a $215 \mathrm{~km}$ swath. Rainrate is derived from the radar data in much the same way as surface based radars using a radar reflectivity - rainrate (Z-R) relationship. When compared to ground based rain-gauge measurements, the uncertainty in PR rainrate was estimated (over western Africa) to be $1.6 \mathrm{~mm} /$ day $\left(0.07 \mathrm{~mm} \mathrm{~h}^{-1}\right)$ for data aggregated over a $2.5^{\circ}$ domain (Nicholson et al., 2003). The TRMM-PR 2A25 precipitation product from September 2006 was acquired for this research. Each 2A25 file contains both vertical profiles and total column estimates of radar reflectivity and rainfall rate. We use the total column rainrate product to compare with the independent atmospheric, cloud, and aerosol observations. Instantaneous rainrates are converted into daily averages as described below. TRMM-PR also separates stratiform from convective precipitation using the observed reflectivity characteristics and computes stratiform and convective rainrate for both rain types. We also examine the difference between stratiform and convective precipitation coverage and characteristics to determine if certain conditions are more favorable for one or the other.

\subsection{Other data sets}

For illustration purposes, the MOD14 MODIS fire product was obtained for the same time period. MODIS fire product uses a contextual algorithm for fire detection (Morisette et al., 2005) based on strong emission of mid-IR radiation from fires and is available at a $1 \mathrm{~km}$ resolution. In addition, aerosol layer heights for this month are obtained from CALIPSO data. The CALIOP sensor on board the CALIPSO satellite is an active lidar on the CALIPSO satellite provides vertical profiles of backscatter at 532 and $1064 \mathrm{~nm}$ that sample the vertical distribution of clouds and aerosols in the atmosphere (Vaughan et al., 2004). We use both the level 1 backscatter (LID-L1) and the level 2 aerosol-layer height retrievals (ALAY5-V2), which are still in their preliminary stages of validation. Given the largely un-validated nature of this product, we chose to only use it as an illustration tool and not as an input to PCA.

\subsection{Data fusion}

Combining data from NCEP, MODIS, and TRMM is a nontrivial task requiring several steps and important assumptions. The NCEP data represents the lowest common denominator resolution-wise with a grid spacing of only $2.5^{\circ}$. Thus, the higher resolution MODIS and TRMM data are placed onto the NCEP grid for further analysis. For each day, MODIS aerosol and cloud data within a $2.5^{\circ}$ box are assigned the atmospheric conditions within $\pm 3 \mathrm{~h}$ of the nearest available NCEP time. In the area of study, this usually works out to be 12:00 UTC for Terra data and 18:00 UTC for Aqua data. Similarly, available TRMM rainrate information for that day and location are averaged within that box. In doing this, the assumption is made that aerosol, cloud, and atmospheric conditions are relatively uniform within a $2.5^{\circ}$ region. Temporal sampling is another concern. In order to trust the results, valid collocated data should exist for as many days as possible during the one month period. Fortunately, valid data from all sensors exist for at least one third of the total possible number of days (31) with several areas having coincident data available for more than 20 days for each $2.5^{\circ}$ grid cell.

Rainrate information collected over the entire one-day period is averaged into the NCEP box, not just rainrate near the time of the Terra or Aqua overpasses. Since the TRMM not in a polar orbit like Terra or Aqua, limiting the data to only rainrate information available within an hour or two of their overpasses would unacceptably reduce sample size. As a result, the rainrate used here represents a daily averaged value. The assumption is made that aerosol concentrations do not change substantially within a $24 \mathrm{~h}$ period and that the changes to cloud and precipitation properties is also relatively constant for this period of time. The resulting daily, $2.5^{\circ}$ resolution data set contains 25 parameters, 24 of which is used as inputs to principal component analysis and one (TRMM rainrate), which are used to determine whether or not aerosols are influencing precipitation (Table 1). 
Table 1. Mean and standard deviation values for NCEP derived atmospheric conditions and MODIS cloud and aerosol properties for South America during September 2006 for no-rain, rain, and heavy rain $\left(>0.5 \mathrm{~mm} \mathrm{~h}^{-1}\right)$ samples. Variables in italics are not statistically significant to a $99 \%$ confidence level.

\begin{tabular}{|c|c|c|c|c|c|}
\hline Variable & Units & Abbr. & No-Rain & Rain & H-Rain \\
\hline Number & - & $\mathrm{N}$ & 3203 & 4707 & 2642 \\
\hline Latitude & $\circ$ & LAT & $-15.3 \pm 15.8$ & $-10.8 \pm 14.6$ & $-4.2 \pm 12.6$ \\
\hline Longitude & $\circ$ & LON & $-60.6 \pm 11.8$ & $-61.7 \pm 11.9$ & $-63.1 \pm 12.2$ \\
\hline $925 \mathrm{hPa}$ Vertical Vel. & $\mathrm{Pas}^{-1}$ & W925 & $0.04 \pm 0.14$ & $0.03 \pm 0.17$ & $0.0 \pm 0.08$ \\
\hline $850 \mathrm{hPa}$ Vertical Vel. & $\mathrm{Pas}^{-1}$ & W850 & $0.03 \pm 0.13$ & $0.02 \pm 0.16$ & $0.0 \pm 0.09$ \\
\hline 700 hPa Vertical Vel. & $\mathrm{Pas}^{-1}$ & W700 & $0.02 \pm 0.11$ & $0.01 \pm 0.13$ & $0.0 \pm 0.09$ \\
\hline 925 hPa Zonal Vel. & $\mathrm{ms}^{-1}$ & U925 & $-1.5 \pm 5.5$ & $-2.4 \pm 4.9$ & $-3.0 \pm 4.5$ \\
\hline $850 \mathrm{hPa}$ Zonal Vel. & $\mathrm{ms}^{-1}$ & U850 & $-1.2 \pm 6.2$ & $-2.4 \pm 5.4$ & $-3.5 \pm 5.0$ \\
\hline $700 \mathrm{hPa}$ Zonal Vel. & $\mathrm{ms}^{-1}$ & U700 & $-0.2 \pm 7.8$ & $-1.5 \pm 7.1$ & $-3.7 \pm 7.0$ \\
\hline 925 hPa Merid Vel. & $\mathrm{ms}^{-1}$ & V925 & $-0.4 \pm 5.0$ & $-0.2 \pm 5.5$ & $0.4 \pm 3.9$ \\
\hline $850 \mathrm{hPa}$ Merid Vel. & $\mathrm{ms}^{-1}$ & V850 & $-0.4 \pm 5.0$ & $-0.2 \pm 5.1$ & $0.3 \pm 3.9$ \\
\hline 700 hPa Merid Vel. & $\mathrm{ms}^{-1}$ & V700 & $-0.1 \pm 5.0$ & $-0.2 \pm 5.0$ & $0.2 \pm 3.7$ \\
\hline $925 \mathrm{hPa}$ Relative Humid. & $\%$ & R925 & $63.1 \pm 19.9$ & $66.0 \pm 21.9$ & $70.0 \pm 16.2$ \\
\hline $850 \mathrm{hPa}$ Relative Humid. & $\%$ & $\mathrm{R} 850$ & $58.8 \pm 19.9$ & $60.6 \pm 22.2$ & $65.1 \pm 16.4$ \\
\hline 700 hPa Relative Humid. & $\%$ & R700 & $48.2 \pm 23.7$ & $47.8 \pm 26.0$ & $53.3 \pm 20.5$ \\
\hline $925 \mathrm{hPa}$ Temperature & $\mathrm{K}$ & T925 & $291 \pm 7.3$ & $292 \pm 6.4$ & $294 \pm 4.1$ \\
\hline $850 \mathrm{hPa}$ Temperature & $\mathrm{K}$ & $\mathrm{T} 850$ & $287 \pm 6.7$ & $288 \pm 5.9$ & $290 \pm 3.6$ \\
\hline $700 \mathrm{hPa}$ Temperature & $\mathrm{K}$ & $\mathrm{T} 700$ & $278 \pm 6.0$ & $280 \pm 4.7$ & $281 \pm 2.7$ \\
\hline 700-1000 hPa Temp & $\mathrm{K}$ & LAPSE & $-6.7 \pm 3.6$ & $-6.7 \pm 2.9$ & $-7.1 \pm 2.0$ \\
\hline Aerosol Optical Thick. & - & $A O T$ & $0.32 \pm 0.5$ & $0.30 \pm 0.4$ & $0.31 \pm 0.4$ \\
\hline Cloud Optical Thick & - & COT & $3.9 \pm 2.5$ & $4.2 \pm 2.8$ & $4.4 \pm 2.2$ \\
\hline Cloud Top Pressure & $\mathrm{hPa}$ & CTP & $779 \pm 100$ & $764 \pm 102$ & $761 \pm 97$ \\
\hline Liquid Water Path & $\mathrm{g} \mathrm{m}^{-2}$ & LWP & $25.0 \pm 18.4$ & $27.5 \pm 19.6$ & $30.2 \pm 17.3$ \\
\hline Cloud Fraction & $\%$ & $C F$ & $11.6 \pm 12.0$ & $12.4 \pm 12.8$ & $11.5 \pm 11.5$ \\
\hline Droplet Effective Radius & $\mu \mathrm{m}$ & RAD & $9.9 \pm 2.2$ & $10.1 \pm 2.4$ & $10.5 \pm 2.1$ \\
\hline
\end{tabular}

\section{Principle Component Analysis (PCA)}

The statistical technique of PCA enables the reduction of multiple and highly correlated variables from multiple data sources into a fewer number of independent variables, each with a unique physical interpretation (Wilks, 2006). The initial step in PCA is the calculation of a linear correlation matrix $(\mathbf{R})$ from the normalized data set $(\mathbf{Z})$, where the mean values have been subtracted out. Here, $\mathbf{Z}$ represents an $m \times n$ array where $m$ is the number of input variables and $n$ is the sample size of the daily data set. For this research, $m=24$ representing the combination of atmospheric, cloud, and aerosol properties (Table 1). Location is also included so that the spatial dependence between these conditions can be taken into account. Rainrate is held out as the comparison variable used later to test the aerosol indirect effect hypothesis. The correlation matrix is computed from the combined aerosol, cloud, meteorology dataset where each data point represents data at a specific $2.5^{\circ}$ grid cell for an individual day for all data during a one month period.

Once the correlation matrix is computed, eigenvalues $(\lambda)$ and vectors ( $\square$ ) are calculated using Eq. (1).

$E^{-1} R E=\lambda$
The correlation matrix and eigenvectors are $m \times n$ arrays with eigenvalues being a one-dimensional array of size $m$. Weighting coefficients (A) are calculated from the eigenvalues and vectors by applying Eq. (2), where $\lambda_{m}$ is a matrix of size $m \times m$ where the diagonal value is set to 1 . Otherwise, $\lambda_{m}$ is zero. Weighting values range in magnitude from -1.0 to 1.0 with 0 indicating no contribution from an input variable to the new $\mathrm{PC}$ variable.

$A=E \sqrt{\lambda_{m}}$

Once the weights have been determined, $\mathrm{PC}$ variables $(\mathbf{F})$ can be derived from the raw data $(\mathbf{Z})$ using Eq. (3). Solving for F produces the final PC variable solution given by Eq. (4).

$Z=F A^{T}$

$F=Z A\left(A^{T} A\right)^{-1}$.

The magnitude of an eigenvalue relative to the total variance of the dataset can be thought of as the degree of variance explained by a new variable. The larger the eigenvalue, the more "important" its information is relative to the entire dataset. Each eigenvalue and eigenvector is associated with a would-be PC variable and defines the physical content of that 


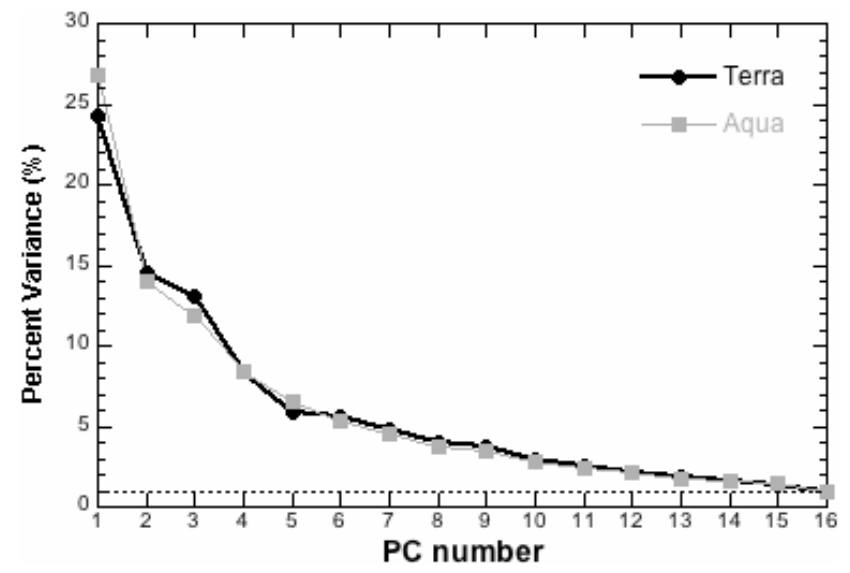

Fig. 2. First 16 eigenvalues derived from the 24 parameter dataset from both Terra and Aqua satellites. Note the values are in close agreement for both sets of data. Dotted line indicates the amount of variance that would be explained by random noise, which occurs at approximately PC16. Thus, higher order PC variables are not retained.

variable via the linear weightings derived from the eigenvectors. It is important to note that this form of PCA only takes into account linear combinations of data; thus, primarily non-linear interactions will not be evident from this analysis. PC variables are ordered in such away that the first variable (PC1) accounts for the greatest variance in the raw data with the next (PC2) accounting for the next highest amount of variance and so on (Fig. 2). Eigenvalues are also used to determine the proper number of new variables (dimensions) to create from the original dataset. For this work, the total number of pseudo-variables is truncated to 16 instead of the possible maximum of 24 since the 17th and larger dimensions account for less than $1 \%$ of the total variance are likely dominated by random noise (Jones et al., 2004). A similar threshold was attained by comparing our eigenvalues with those created from a dataset created from a random number generator having the same sample size and total variance as the original dataset. If the eigenvalues fall below that produced by random noise, then it and higher order dimensions should be removed. For this case, the highest order PC produced from the random data set explained $1.3 \%$ of the total variance.

To further reduce noise in the new dataset, weightings less than \pm 0.2 are set to zero before the creation of the final PC variables. Richman and Gong (1999) showed that including lower weights increased noise and decreased the viability of the new variables. The magnitude of these thresholds $( \pm 0.2$ to 0.3 ) were derived by analyzing multiple atmospheric data sets, and these values were found to produce the best representation of the data in PC space. If the resulting weights lie near this threshold, then their physical contribution to the corresponding PC variable will be considered low. These steps are important for this research as the data used here
Table 2. Correlation matrix between MODIS AOT and selected cloud parameters showing the overall low correlations between AOT and cloud properties. Importantly, AOT and Rc are not negatively correlated as predicted by the Twomey effect.

\begin{tabular}{lrrrrr}
\hline Correlation & AOT & $R_{\mathrm{c}}$ & COT & LWP & CTP \\
\hline AOT & 1.00 & 0.17 & -0.05 & -0.05 & -0.15 \\
$R_{\mathrm{c}}$ & 0.17 & 1.00 & 0.05 & 0.30 & -0.12 \\
COT & -0.05 & 0.05 & 1.00 & 0.93 & -0.21 \\
LWP & -0.05 & 0.30 & 0.93 & 1.00 & -0.19 \\
CTP & -0.15 & -0.12 & -0.21 & -0.19 & 1.00 \\
\hline
\end{tabular}

contains a high degree of random variability that needs to be filtered out as much as possible prior to further analysis. The end result of this process is a data set containing $16 \mathrm{PC}$ variables, some of which contain physical signals that related to rainrate while others contain non-physical signals not associated with rain. Principle component statistics for both Terra and Aqua were computed and very little difference between the two was observed. Thus, the following analysis primarily concentrates on the Terra data alone.

Uncertainties present in the raw data, especially those associated with aerosol and cloud parameters, remain present within the PC data set. However, the PCA methods used here to mitigate some uncertainties to some degree. Assuming the uncertainties are randomly distributed, they should show up in the higher order PC variables where little to no physical signal exists. The weighting threshold of 0.2 has a similar effect. The result is that some uncertainty is filtered out when removing random noise within the data set. However, uncertainties that show a dependence between one variable and other (e.g. AOT and cloud parameters) will remain present, though it is hoped they may also be grouped into higher order $\mathrm{PC}$ variables separate from the physical signals that dominate the lower order PCs.

\section{Results}

\subsection{Raw data}

Prior to the analysis of variables created using PCA, the raw observations are briefly examined relative to precipitation occurrence and intensity to determine what, if any significant linear relationships exist. Without considering precipitation, aerosol effects may still manifest themselves as significant correlations between AOT and certain cloud properties such as $R_{\mathrm{c}}$, COT, LWP, and CTP assuming collocated changes in atmospheric conditions are not a significant factor. Recall that for a given atmospheric liquid water content, increasing AOT associated with an increase in aerosol number density will increase the number of $\mathrm{CCN}$, decreasing the size of individual cloud droplets. Thus, AOT and cloud droplet effective radius $\left(R_{\mathrm{c}}\right)$ should be negatively correlated all other 
things being equal. Of course, things are much more complicated than what this idealized scenario suggests. Table 2 lists the linear correlation coefficients between these five parameters and the only obvious correlation is between COT and LWP, which is expected since they both represent a measure of cloud thickness. AOT is weakly positively correlated $(0.17)$ with $R_{\mathrm{c}}$, opposite that expected when aerosol indirect effects are occurring. A weak negative correlation $(-0.15)$ also exists between AOT and CTP indicating that increasing AOT may correspond to lower toped clouds. However, both these correlations lie on the edge of statistical significance preventing any major conclusions being drawn from these relationships thus far.

To determine if aerosol effects are localized to certain regions in South America, the correlation between AOT and $R_{\mathrm{c}}$, COT, and CTP is calculated for daily data within each $2.5^{\circ}$ box and plotted in Fig. 1d-f. No evidence for the first indirect effect exists since AOT and $R_{\mathrm{c}}$ are not negatively correlated where AOT is highest (Fig. 1d). The correlation between AOT and COT (and CTP) shows more of a spatial dependence relative to the location of maximum AOT in central South America (Fig. 1e). For this area, AOT and COT are negatively correlated while AOT and CTP are positively correlated (Fig. 1f). This would indicate that higher aerosol concentrations are associated with thinner clouds with lower heights compared to other regions. This is not consistent with the second aerosol indirect effect, but is consistent with the semi-direct effect whereby absorbing aerosols (such as the soot and black carbon produced by the biomass burning) warm portions of the atmosphere, increasing atmospheric stability, which decreasing the favorability of the environment for the formation of clouds and precipitation.

To determine if aerosol effects are evident relative to precipitation measurements, data are first separated into no-rain, rain, and "heavy" rain only $\left(>0.5 \mathrm{~mm} \mathrm{~h}^{-1}\right)$ samples to examine if any significant differences in variables exist for rain vs. no rain. Table 1 lists mean and standard deviation values for selected variables for each of the three samples. CTP, $\mathrm{COT}$, and $R_{\mathrm{c}}$ all slightly larger in the rain and heavy-rain samples compared to the no-rain samples, as would be expected. Conversely MODIS cloud fraction does not show much difference, and remains quite low $(<15 \%)$ for all three samples. Since only data with valid AOT retrievals are used, at least some cloud-free sky must exist within each pixel, so $100 \%$ cloudy regions are not included, reducing cloud fraction compared to if AOT retrievals were not a concern. Atmospheric wind speed and relative humidity are also greater in the rain sample, while average vertical velocity is tiny for all three samples. The latter is primarily a result of the poor resolution of the NCEP data that prevents sampling of the vertical motion associated with mesoscale features (Lin et al., 2006).

Overall, these are differences of only a few percent and standard deviations between all samples overlap by a large margin. Still, statistical significance testing using both Stu-

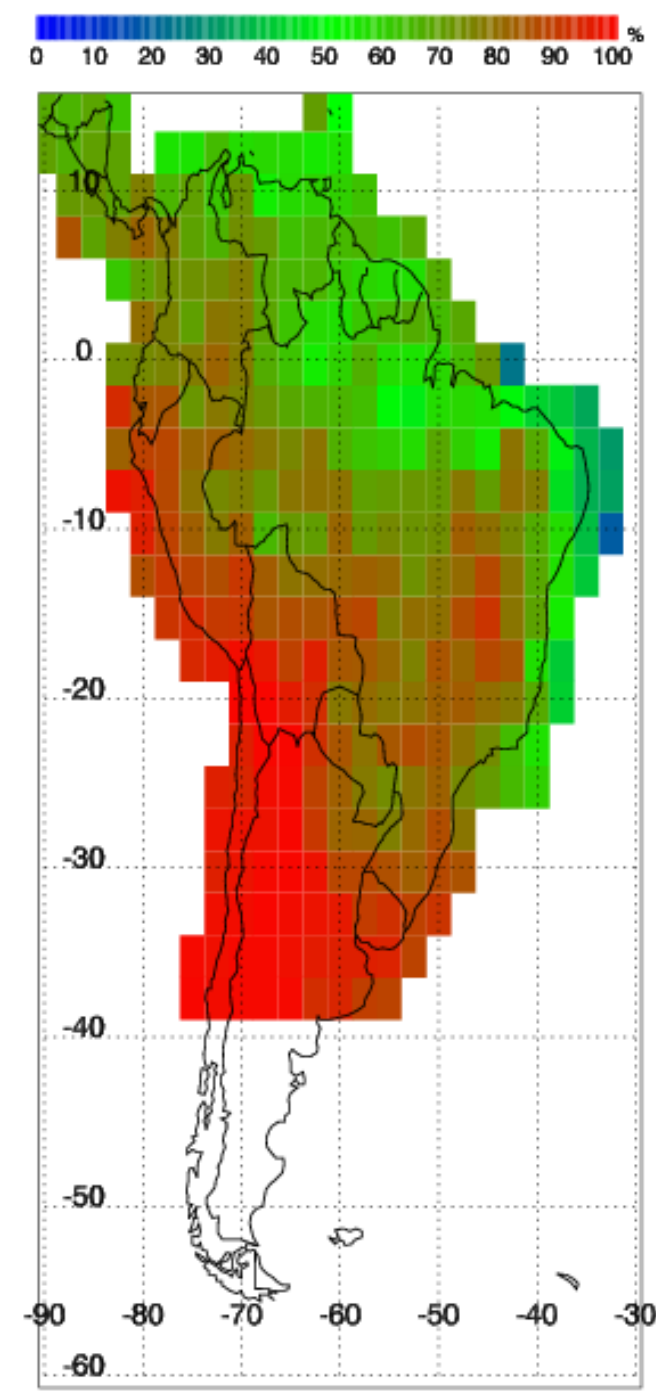

Fig. 3. Percentage of precipitation in each $2.5^{\circ}$ grid box from TRMM-PR defined as stratiform precipitation. Red coloring indicates that precipitation is mostly stratiform, while green coloring indicates a $50-50 \%$ mix.

dent's $\mathrm{T}$ and the nonparametric Wilcoxon-Mann-Whitney methods (Wilks, 2006) show that the differences between norain and heavy rain samples are significant to at least a $99 \%$ confidence level for all parameters related to atmospheric conditions and cloud properties with the exception of V700 and MODIS cloud fraction. These differences remain significant when compared against the sample mean variables calculated from the entire dataset. Breaking down precipitation into stratiform and convective components, we find that monthly mean convective rainrate is much greater the stratiform rainrate ( 3.3 vs. $0.7 \mathrm{~mm} \mathrm{~h}^{-1}$ ). Convective rain is more likely $(50 \%)$ to occur further north compared to southern regions $(10 \%)$ and is associated with stronger easterly winds and greater moisture as shown in Fig. 3. AOT is slightly 
Table 3. Weighting coefficients produced using PCA that are used to generate the new PC variables. Values less than 0.2 are set to 0.0 , which are indicated by blank spaces. First row of values is the amount of variance explained by the corresponding PC variable.

\begin{tabular}{|c|c|c|c|c|c|c|c|c|c|c|c|c|c|c|c|c|}
\hline & PC1 & $\mathrm{PC} 2$ & PC3 & PC4 & PC5 & PC6 & PC7 & PC8 & PC9 & $\mathrm{PC} 10$ & PC11 & PC12 & PC13 & $\mathrm{PC} 14$ & PC15 & PC16 \\
\hline $\operatorname{VAR}(\%)$ & 24.3 & 14.6 & 13.1 & 8.4 & 5.9 & 5.6 & 4.8 & 4.0 & 3.8 & 2.9 & 2.5 & 2.2 & 1.9 & 1.5 & 1.4 & 1.0 \\
\hline LAT & 0.85 & -0.28 & & & & & & & & & & & & & & \\
\hline LON & & & -0.55 & 0.26 & -0.39 & & -0.40 & & -0.39 & & & & & & & -0.20 \\
\hline U925 & -0.55 & 0.32 & 0.44 & & & & 0.31 & & & 0.36 & & & & & & -0.20 \\
\hline V925 & & -0.66 & & 0.26 & & -0.49 & & 0.29 & & & -0.23 & & & & & \\
\hline W925 & -0.47 & & & -0.79 & & & & & & & & 0.24 & & & & \\
\hline R925 & 0.30 & -0.47 & 0.53 & & -0.24 & 0.22 & & -0.26 & 0.26 & & -0.32 & & & & & \\
\hline T925 & 0.88 & 0.22 & & & & -0.20 & & & & 0.20 & & & & & & \\
\hline U850 & -0.67 & 0.43 & 0.36 & & & & 0.22 & & & 0.32 & & & & & & \\
\hline V850 & -0.25 & -0.76 & & 0.29 & & -0.42 & & & & & & & & & & \\
\hline W850 & -0.49 & -0.24 & & -0.78 & & & & & & & & & & & & \\
\hline R850 & 0.44 & -0.27 & 0.58 & & -0.42 & & & & 0.25 & & & & & & & \\
\hline T850 & 0.87 & 0.25 & & & & & & & & & & & & & & \\
\hline U700 & -0.74 & 0.32 & 0.20 & & & & & & & & & & -0.22 & & & 0.32 \\
\hline V700 & -0.26 & -0.70 & & 0.27 & & & & & & & 0.24 & & & 0.30 & & \\
\hline W700 & -0.34 & -0.45 & & -0.49 & & & & -0.21 & & & & -0.50 & & & & \\
\hline R700 & 0.41 & 0.21 & 0.46 & & -0.37 & -0.34 & & & & & 0.37 & & -0.27 & & 0.22 & \\
\hline T700 & 0.84 & & & -0.27 & & & & & & 0.22 & -0.28 & & & & & \\
\hline LAPSE & -0.35 & 0.40 & & & 0.53 & & 0.30 & & 0.27 & & -0.22 & -0.26 & & & & \\
\hline AOT & 0.20 & 0.45 & & & & -0.47 & & & -0.39 & -0.42 & & & 0.27 & & & \\
\hline COT & 0.25 & -0.28 & 0.70 & & & 0.30 & & 0.31 & -0.32 & & & & & & & \\
\hline CTP & & -0.34 & -0.53 & & & 0.20 & 0.53 & & & & & & & -0.28 & 0.27 & \\
\hline LWP & 0.29 & -0.30 & 0.70 & & 0.28 & 0.26 & & & -0.38 & & & & & & & \\
\hline $\mathrm{CF}$ & & 0.37 & 0.42 & & 0.27 & & -0.62 & & & & & & 0.22 & -0.29 & 0.21 & \\
\hline RAD & 0.24 & & 0.21 & & 0.51 & & & -0.63 & -0.27 & & & & -0.26 & & & \\
\hline
\end{tabular}

higher for the no-rain compared to the heavy rain sample ( 0.32 vs. 0.30$)$, but this difference is also not statistically significant. Similarly, AOT is also lower for the convective rain sample compared to the stratiform rain sample $(0.28$ vs. 0.31 ).

For the heavy rainrate $\left(>0.5 \mathrm{~mm} \mathrm{~h}^{-1}\right)$ sample only, Fig. 4 shows the relationship between selected atmospheric, cloud, and aerosol parameters relative to rainrate. The various number density plots indicate a generally poor relationship between these parameters. A weak linear relationship exists between rainrate and $850 \mathrm{hPa}$ vertical velocity where rainrate decreases as downward vertical motion (positive values in pressure coordinates) increases. However, the magnitude of the correlation is quite small, being only -0.1 . Neither COT nor $R_{\mathrm{c}}$ show any significant relationship, while AOT has a weak positive correlation (0.13) to rainrate. Even when the correlations are considered statistically significant, they do not provide conclusive evidence that a single atmospheric, cloud, or aerosol parameter is related to rainrate or not, since all these parameters are highly correlated with each another. Better relationships might be found when comparing the PC variables to rainrate, since each variable is representative of a unique set of atmospheric, cloud, and aerosol properties, some combination of which may be sensitive to rainrate.

\subsection{PC data}

The application of PCA produces 16 new variables with unique physical interpretations that can be inferred from the weighting coefficients use to create each variable (Table 3 ). The first PC variable (PC1) accounts for $25 \%$ of the total variance and is primarily derived from the prevailing atmospheric conditions and their location. Positive values of PC1 indicate higher latitudes, a stronger easterly (from east) wind component (this can also be interpreted as corresponding to weaker westward component of wind), relative humidity, and upward vertical motion between 1000 and $700 \mathrm{hPa}$. PC1 also receives a negative weighting from the lapse rate parameter indicating that increasingly negative values of lapse rate (i.e. greater instability) are correlated with more positive values of $\mathrm{PC} 1$. Latitude is also important, with a weighting coefficient of 0.85 in PC1. What this means is that atmospheric conditions favorable for clouds and precipitation are more likely to be found in the northern portion of the continent (e.g. Amazon), which is evident from Fig. 1b. MODIS cloud properties are also present with small positive weightings $(\sim 0.25)$ associated with COT, LWP, and $R_{\mathrm{c}}$. Thus, positive values of PC1 are clearly indicative of atmospheric conditions in which clouds and precipitation are more likely to occur.

Continuing on to $\mathrm{PC} 2$, which accounts for $15 \%$ of the total variance, we find a more interesting interaction between atmospheric, cloud, and aerosol weightings. Positive values of PC2 are associated with a more northerly component of wind and upward vertical motion at 850 and $700 \mathrm{hPa}$, with the larger weighting coefficient at $700 \mathrm{hPa}$. The humidity weighting coefficients are interesting in that they are negative at 925 and $850 \mathrm{hPa}$, but positive at $700 \mathrm{hPa}$. Thus, positive 

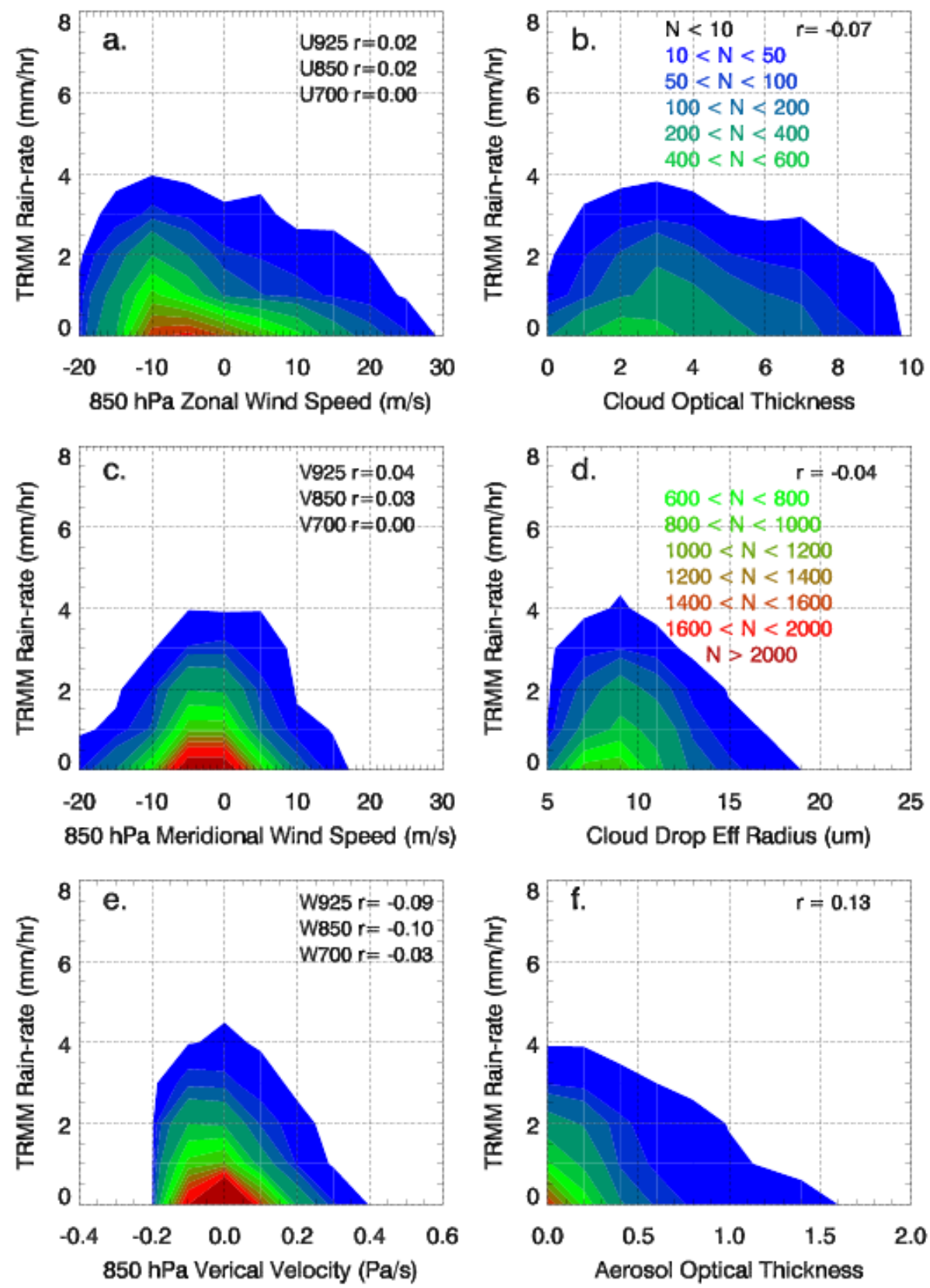

Fig. 4. Number density plot of TRMM rainrate vs. selected atmospheric, cloud, and aerosol variables for September 2006 including linear least squares where $N$ represents the number of data points with a $1.0 \mathrm{~mm} \mathrm{~h}^{-1}$ bin. Parameters compared to rainrate include zonal, meridional, and vertical velocities as well as COT, $R_{\mathrm{c}}$, and AOT. Linear correlation coefficients $(r)$ between each parameter and rainrate are shown.

values of PC2 correspond to dryer air near the surface, but increasing humidity at $700 \mathrm{hPa}$. The sign of the lapse rate coefficient is consistent with this, as positive values would indicate the presence of an inversion layer in the lower atmosphere. COT and LWP are negatively weighted indicating that atmospheric conditions associated with increasing PC2 values are not conducive for liquid water cloud formation, though cloud fraction and CTP have weighting coefficients such that positive values of $\mathrm{PC} 2$ indicate more cloud cover at higher levels corresponding to $700 \mathrm{hPa}$ layer where the humidity weighting is also positive. MODIS AOT also has a significant positive weighting (0.45), which indicates that the same atmospheric conditions not favorable for thick clouds near the surface also correspond to the highest AOT.

Recall that the relationship between only AOT itself and rainrate is weakly positive (0.13), opposite that expected for 

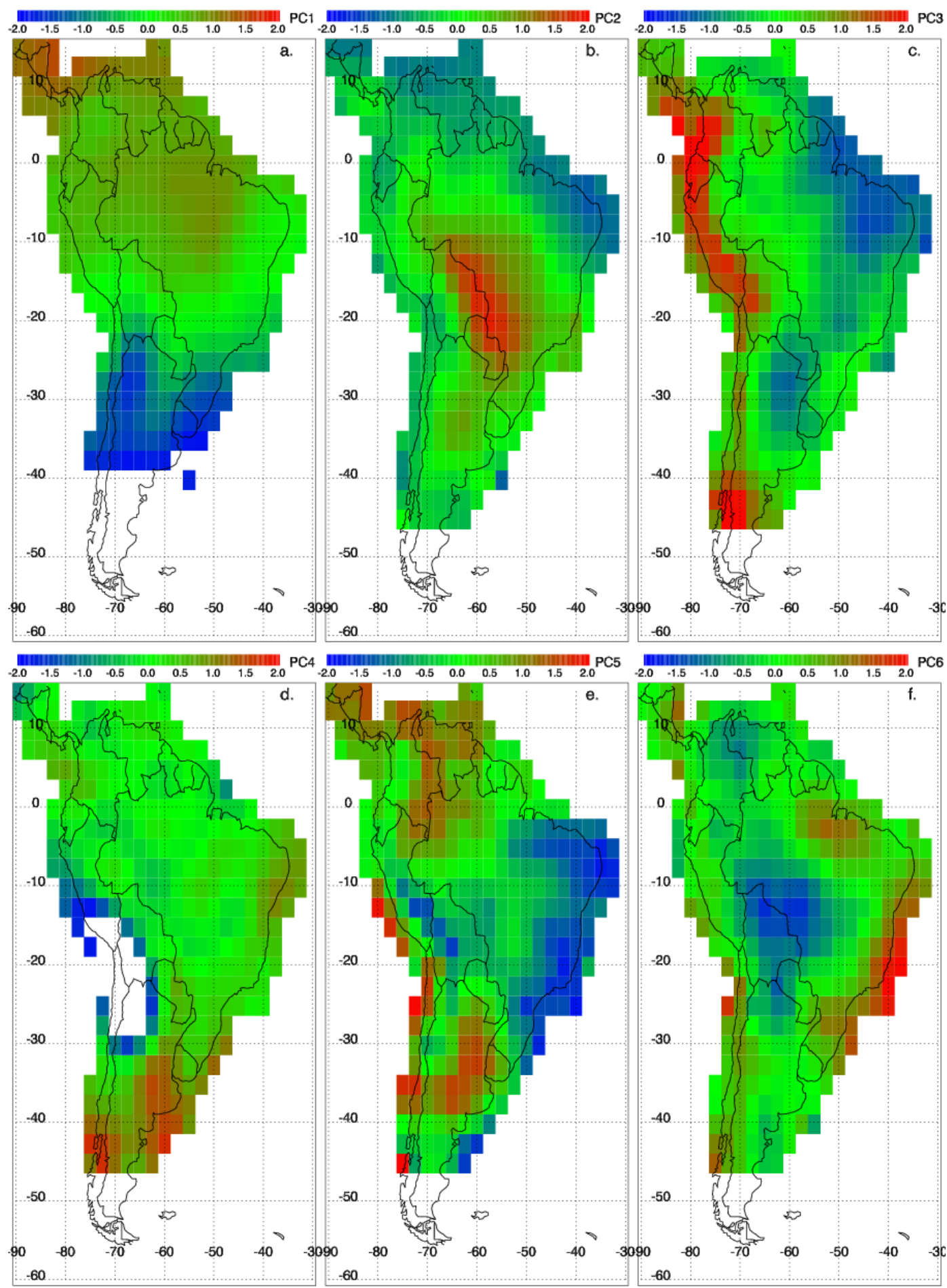

Fig. 5. Spatial plots of PC1-6 created using the combined atmospheric, cloud, and aerosol property data set. Reds indicate positive PC values while blues indicate negative PC values. Values larger than \pm 2.0 are set to \pm 2.0 in all figures.

the aerosol effect to warm-process precipitation, but consistent with an increase in convective precipitation (Lin et al., 2006). In PC2, increasing AOT corresponds to conditions that are increasingly unfavorable for precipitation. The weighting coefficients for AOT and cloud fraction are also of the same sign, consistent with the second indirect effect. The positive relationship between stability and AOT may be an indicator that radiative effects are dominating 

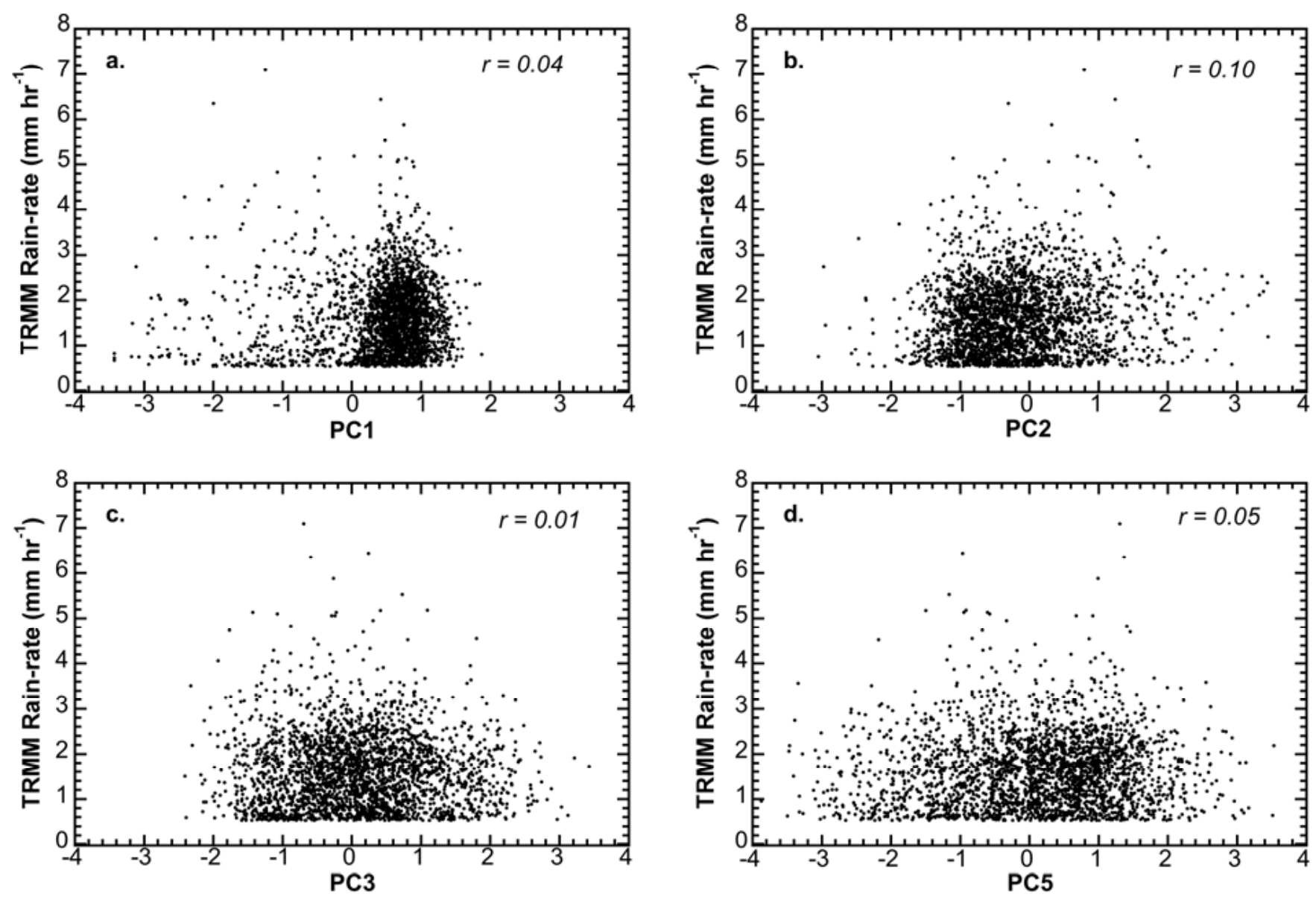

Fig. 6. Scatter plots of rainrate vs. selected PC variables, which are statistically significant and separating rain from no-rain samples. Unfortunately, significant relationships with rainrate itself could not be found as evident by the poor correlations given in each figure.

microphysical effects, which is quite similar to the results of Rosenfeld et al. (2008) who observed a decrease in CAPE when AOT $>0.25$. These results are also consistent with the spatial correlation plots of AOT vs. COT and CTP shown in Fig. 1e, f where regions associated with the highest AOT had the thinnest and lowest clouds. Note that the spatial plot of PC2 in Fig. $6 \mathrm{~b}$ is quite similar to the AOT - cloud parameter correlation plots. Given these relationships, at least a portion of the inhibition of precipitation due to aerosols (if it is indeed occurring) is accounted for by PC2.

The next PC variable, PC3, accounts for $13 \%$ of the total variance with positive values associated with a greater westward component of wind, higher humidity, and higher COT, LWP, cloud fraction, $R_{\mathrm{c}}$, and lower CTP all of which indicate a strong sensitivity to cloud depth and coverage. Longitude is also highly weighted $(-0.55)$ indicating that the deeper clouds and greater atmospheric humidity are more likely further west associated with convergence near the Andes mountains in western South America, which is apparent when comparing Figs. 1c and 6d. Continuing to PC4, we find that it primarily consists of vertical motion parameters weakly associated with northerly winds and further eastward longitude. No significant weightings from clouds and aerosol variables are present. PC5 contains significant weightings from longitude, humidity at all levels, lapse rate, and cloud parameters including LWP, cloud fraction, and $R_{\mathrm{c}}$. Interestingly, the cloud weightings are inversely proportional to the humidity weightings indicating the presence of thicker clouds in lower moisture environments. Positive values of PC6 are primarily sensitive to northerly winds at 925 and $850 \mathrm{hPa}$, with negative weighting associated with AOT. Less significant positive weightings also exist for COT, CTP, and LWP. In other words, increasing values of PC6 represent a greater northerly component to the wind associated thicker, but lower level clouds and a decreasing aerosol content. The importance of AOT in PC6 (Fig. 6f) is clearly evident in its similarity to the AOT plot in Fig. 1a.

By PC7, only $5 \%$ of the total variance is being explained and the physical interpretations become less clear. Of particular interest with respect to this research, is which of these higher order PC variables contain evidence for more traditional aerosol indirect effects. Significant weighting 


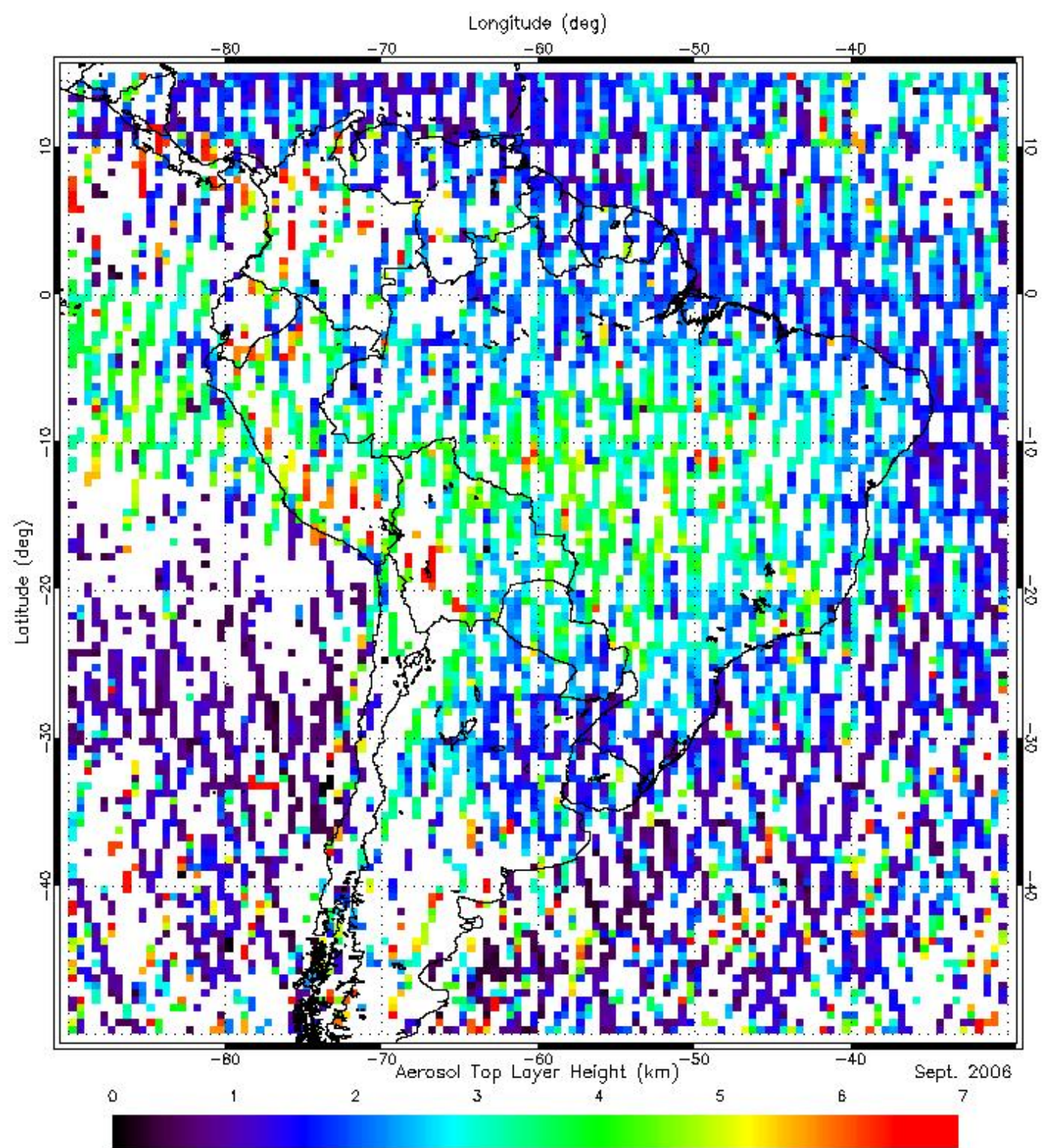

Fig. 7. CALIPSO level 2 aerosol heights $(\mathrm{km})$ over South America during September 2006. In the central portion of the continent where biomass burning and AOT is highest, aerosols are present up to $4 \mathrm{~km}$ above the surface.

coefficients exist for AOT in PC9, 10, and 13. In PC9, the weighting coefficients for AOT, COT, LWP, and $R_{\mathrm{c}}$ are all the same sign, which would not be expected if this variable corresponds to aerosol effects. This relationship would occur if AOT increases in the vicinity of clouds due to either aerosol swelling and/or small cloud droplets being identified as aerosols by the retrieval algorithm. Since it is a retrieval problem, it should be unrelated to other atmospheric variables present in the data set, which appears to be the case as no weights greater than 0.2 are present from atmospheric variables with the sole exception of 925 and $850 \mathrm{hPa}$ humidity. The largest weighting coefficient in PC10 is also from AOT, with smaller contributions from the zonal component of wind speed. As expected, the spatial distribution of PC10 is very similar to that of AOT alone, though it is inversely correlated. Given the lack of cloud property weightings in this variable, it is also unlikely to be representative of indirect effects. PC13, while only explaining $2 \%$ of the total variance, is comprised of AOT, cloud fraction, and $R_{\mathrm{c}}$ among others. The weighting coefficients for AOT and cloud fraction are of the same sign, with the coefficient for $R_{\mathrm{c}}$ being the opposite. This is exactly the relationship expected for the Twomey effect. However, the weighting coefficients are low $(<0.3)$ calling into question their true significance. Positive values of PC13 are associated with higher AOT and smaller $R_{\mathrm{c}}$; thus, if this effect is reducing the amount of precipitation 
Table 4. Mean and standard deviations for PC1-16 for no-rain, rain, and heavy rain samples. Variables in italics are not statistically significant to a $99 \%$ confidence level.

\begin{tabular}{lccc}
\hline $\begin{array}{l}\text { Variable } \\
\text { Number }\end{array}$ & $\begin{array}{c}\text { No-Rain } \\
3203\end{array}$ & $\begin{array}{c}\text { Rain } \\
4707\end{array}$ & $\begin{array}{c}\text { H-Rain } \\
2642\end{array}$ \\
\hline PC1 & $-0.15 \pm 1.1$ & $0.1 \pm 0.9$ & $0.46 \pm 0.7$ \\
PC2 & $0.05 \pm 1.1$ & $-0.04 \pm 1.0$ & $-0.18 \pm 0.8$ \\
PC3 & $-0.03 \pm 1.1$ & $0.02 \pm 1.0$ & $0.12 \pm 1.0$ \\
PC4 & $0.04 \pm 1.1$ & $-0.02 \pm 1.0$ & $0.08 \pm 0.7$ \\
PC5 & $-0.12 \pm 1.3$ & $0.08 \pm 1.3$ & $0.12 \pm 1.2$ \\
PC6 & $0.00 \pm 1.2$ & $0.00 \pm 1.1$ & $-0.15 \pm 1.0$ \\
PC7 & $0.09 \pm 1.2$ & $-0.06 \pm 1.1$ & $0.03 \pm 1.1$ \\
PC8 & $-0.04 \pm 1.4$ & $0.03 \pm 1.3$ & $-0.08 \pm 1.2$ \\
PC9 & $-0.05 \pm 1.2$ & $0.04 \pm 1.2$ & $0.14 \pm 1.2$ \\
PC10 & $-0.04 \pm 1.6$ & $0.03 \pm 1.4$ & $0.10 \pm 1.3$ \\
PC11 & $0.08 \pm 1.5$ & $-0.05 \pm 1.4$ & $0.12 \pm 1.4$ \\
PC12 & $-0.06 \pm 1.3$ & $0.04 \pm 1.3$ & $0.00 \pm 1.1$ \\
PC13 & $0.02 \pm 1.4$ & $-0.02 \pm 1.7$ & $0.00 \pm 1.6$ \\
PC14 & $-0.09 \pm 2.4$ & $0.06 \pm 2.1$ & $0.05 \pm 1.9$ \\
PC15 & $0.05 \pm 2.7$ & $-0.04 \pm 2.5$ & $0.19 \pm 2.4$ \\
PC16 & $-0.03 \pm 1.8$ & $0.02 \pm 1.7$ & $-0.01 \pm 1.7$ \\
\hline
\end{tabular}

through decreasing cloud droplet size, then the relationship between PC13 and precipitation should be negatively correlated. (The larger PC13, the higher the corresponding AOT, which according to theory indicates that precipitation should decrease).

\subsection{Comparison of $\mathrm{PC}$ variables with rainrate}

As with the raw variables, and mean and standard deviation of each PC variable is compared across no-rain, rain, and heavy rain samples (Table 4). Differences in several PC variables are clearly evident between no-rain and heavy rain samples. For example, PC1 increases by 0.6, PC2 decreases by 0.23 , and PC 3 increases by 0.15 , differences of more than $100 \%$. Recall that PC1 includes significant weighting coefficients from many atmospheric variables, which interact in a manner such that positive values of PC1 should indicate an environment (and location) more favorable for precipitation. PC2 includes a linear combination of atmospheric and cloud variables along with AOT, where positive values indicate less low-level moisture, greater low-level stability, thinner clouds, and higher AOT. Thus, highly positive values should be associated with less rainfall while negative values more. This is indeed the case as PC2 values are most negative for the heavy rain sample (Table 4) providing further evidence that AOT and the occurrence of precipitation are negatively correlated. However, recall that $R_{\mathrm{c}}$ is not significantly weighted in PC2, so it is unlikely that PC2 is an indicator of the first aerosol indirect effect, but more likely a reflection of the semi-direct effect. Despite the presence of AOT - cloud parameter relationships similar to that expected by Lin et al. (2006), values for PC2 are lower for convective precipitation compared to stratiform precipitation. Thus, it would appear that if the convective effect is occurring over this domain, it is more than being offset by the decrease in precipitation due to other aerosol effects. Values for PC 3 increase from no-rain to heavy rain samples as expected since this variable is positively correlated with increased humidity and cloud thickness in the mountainous convergence zone in western South America. The differences between no-rain and heavy rain sample means for PC1-3 are statistically significant to at least a $99 \%$ confidence level using the same tests as before.

Moving on to higher order PC variables, differences become less clear. PC4 is not statistically significant. PC5 increases from no-rain to rain samples, even though it is negatively correlated with humidity and positively correlated with stability. However, $R_{\mathrm{c}}$ is positively weighted indicating that positive PC5 values are correlated with larger water droplets, which would increase the likelihood of collision and coalescence and thus precipitation. PC6 is lower for the heavy rain sample, neither this difference nor the difference between the no-rain sample and the total sample means are statistically significant. While the difference for some higher order PC variables are statistically significant (PC9, PC10), the overall weak weighting coefficients in these variables make physical interpretations difficult. In fact, some of these higher order variables may be a reflection of various uncertainties and biases in the raw dataset as suggested by PC9, whose weightings correspond to those expected when AOT increases in close proximity to clouds.

To determine whether or not the physical relationships inferred from PC variables are indeed real, we analyze as example using CALIPSO data, which shows the location of aerosol and cloud layers. A monthly mean plot of aerosol layer height derived from CALIPSO level 2 data shows that the smoke aerosols exist at least $4 \mathrm{~km}$ above ground level in the west central portion of the continent (Fig. 7). A vertical profile of $532 \mathrm{~nm}$ backscatter over South America on 22 September 2006 at 18:00 UTC clearly shows the significant aerosol concentration between $-20^{\circ} \mathrm{S}$ and $0^{\circ} \mathrm{N}$, with aerosols ranging from near the surface all the way up to $4 \mathrm{~km}$ in altitude. Recall that for the semi-direct effect to occur, large concentrations of elevated, absorbing aerosols must exist, and the CALIPSO data demonstrates that to be the case at least for the month of data analyzed. The positive weighting coefficient for stability in PC2 is consistent with this effect occurring, though the stability parameter is defined at from a slightly lower level $(1000-700 \mathrm{hPa})$. Also note that AOT and $R_{\mathrm{c}}$ are positively correlated overall, and no PC variable that includes inverse relationship between the two provided a statistically significant difference when compared to no-rain vs. heavy rain samples. If aerosols are affecting the likelihood of precipitation for the time period and spatial domains examined here, it is likely more through semi-direct effects and not traditional aerosol indirect effects. 


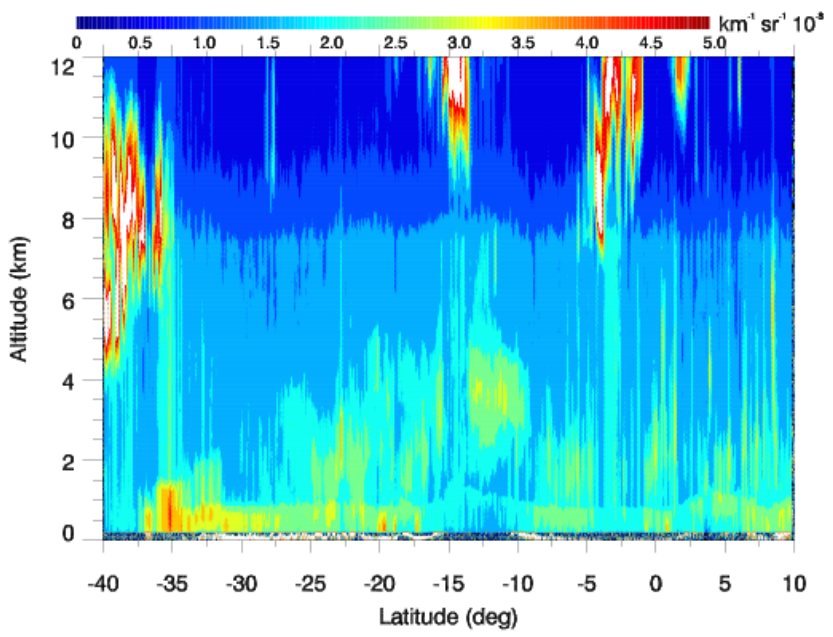

Fig. 8. CALIPSO $532 \mathrm{~nm}$ backscattered radiation from an overpass on 22 September 2006 at 18:00 UTC. A thick aerosol layer exists between $-20^{\circ} \mathrm{S}$ and $0^{\circ} \mathrm{N}$ that corresponds to the region of maximum AOT shown in Figure 1a. Note that in this example, significant aerosol concentrations are present from near the surface up to $4 \mathrm{~km}$.

To determine if the physical relationships expressed by individual PC variables are affecting rainrate, linear regression models between each statistically significant PC variable from above are created between them and TRMM rainrate. Unfortunately, as with the raw atmospheric and cloud parameters, statistically significant linear relationships between rainrate and PC variables are not found (Fig. 6). Further stratifying the data into convective vs. stratiform precipitation did not improve the significance of the PC variables compared to rainrate itself. Given the spatial and temporal resolution differences between the data sets and their various uncertainties, this result was not completely unexpected. Still, we are able to show the usefulness of PC variables in examine how aerosol concentrations are related to the probability of rain occurring, which is an important step forward. It is important to note that we are not attempting to create a predictive model; this research is keyed to showing that a statistically significant relationship exists.

\section{Conclusions}

Overall, we find that atmospheric conditions favorable for precipitation are correlated to a statistically significant level with the occurrence of precipitation observed using TRMMPR rainrate estimates, and this correlation outweighs any aerosol-cloud interactions. We also find that MODIS cloud parameters such as COT, CTP, and $R_{\mathrm{c}}$ show a significant correlation with the occurrence of precipitation where thicker, deeper clouds with larger water droplets are present. A comparison using solely AOT and TRMM-PR rain data does not provide an unambiguous solution as to what, if any, effects aerosols are having on precipitation. Since aerosol, cloud, and the surrounding atmospheric conditions are highly related to one another, this research uses PCA to extract unique physical signals from the combined dataset.

The most important PC variable in terms of total variance explained, PC1, is representative of a linear combination of atmospheric and location parameters associated with favorable conditions for precipitation and is greater for data where rainrate $>0.5 \mathrm{~mm} \mathrm{~h}^{-1}$. PC2 is the more interesting combination as it includes a significant weighting coefficient for AOT in combination with other atmospheric variables. The weighting coefficients for PC2 suggest that larger values of PC2 are associated with greater low-level stability and drier air, which is unfavorable for precipitation. In the case of PC2, higher values correspond to the no-rain sample compared to the rain and heavy rain samples. Also significant in PC2 are the cloud and aerosol components. The weighting coefficient for AOT is positive indicating the larger AOT corresponds to a decreased likelihood for precipitation. Two possible interpretations of this variable exist. First, is that AOT is highly correlated with the atmospheric conditions affecting rainfall present in this variable. Second is that aerosols present within these atmospheric conditions are directly affecting rainfall amounts. The relative importance of one vs. the other interpretation is difficult to quantify using this method, but if aerosol concentrations were not playing at least some role, then AOT should not have a significant weighting in this (or other) parameters related to rainfall amount. The relative weightings in PC2 are consistent with the semi-direct effects tied to warm process clouds, but not microphysical effects since $R_{\mathrm{c}}$ is not included in PC2. The positive AOT weighting coefficient also corresponds to an increase in cloud fraction and lower cloud top temperatures. This relationship was observed by Lin et al. (2006) under the hypothesis that while aerosols are decreasing the efficiency of warm process precipitation, they increase the likelihood of convective precipitation. Even though we are analyzing only liquid water cloud properties, the statistical relationships observed in PC2 are similar to that expected through the convective effect hypothesis with one major exception. If the convective effect was dominant, then heavy precipitation should correspond to higher values of PC2 when in fact the opposite was observed. For the domain studied here, it appears that if the convective effect is occurring, the decrease in precipitation due to more traditional aerosol effects, especially the semi-direct effect where absorbing aerosols warm the atmosphere and increase stability, is still greater.

The difference in PC3 values between no-rain and heavy rain samples also proved significant, with this variable being largely sensitive to greater precipitation amounts, thicker and higher clouds associated with convergence along the western coast of South America near the Andes mountains. Several higher order PC variables show significant differences between no-rain and heavy rain samples, though none appear to be associated with any known aerosol indirect effects. 
Only in PC13 are the AOT and $R_{\mathrm{c}}$ coefficients significant and inversely correlated, which should occur according to the Twomey effect. However, no statistically significant difference in PC13 exists between rain and no-rain samples strongly indicating that if the first aerosol indirect effect is occurring, it is being offset by the other processes described by several other PC variables.

The differences between no-rain and heavy rain values for PC1-3 are much greater in an absolute sense compared to several to the individual atmospheric and cloud properties. Also recall that, combined, these three variables alone account for over $50 \%$ of the total variance. This research clearly emphasizes the usefulness of PCA at extracting different physical signals from a large array of highly correlated data. Using only PC1 and PC2, it is possible to discriminate between conditions favorable for precipitation and those favorable for some form of aerosol effects on clouds and precipitation. Given these results, we are able to conclude that atmospheric conditions are more important to rainrate than aerosol - cloud interactions; however, these interactions are an important secondary factor.

Assuming PC2 is an accurate reflection of the physical processes occurring over South America, then it would appear the radiative effects of absorbing aerosols outweigh the microphysical effects when reducing the probability for stratiform precipitation. This result is consistent with observations from both Lin et al. (2006) and Rosenfeld et al. (2008). In addition, while PC2 would also be sensitive to the convective effect, its values relative to rainrate indicate that any increase in precipitation due to this effect is being more than offset by the reduction in precipitation due to the semi-direct effect. While the consistency of the results across various research efforts cannot be ignored, uncertainties remain large and it remains difficult to prove that the PC variables created here are a reflection of the processes previously described. Comparison with CALIPSO and other forms of data do lend further support to our hypothesis and we strongly believe the weights associated with at least PC1-3 are physically significant. Thus, we believe the use of PCA techniques for the study of aerosol indirect effects is a useful endeavor applicable to future research efforts.

Unfortunately, PC variables did not have statistically significant relationships with rainrate itself, although neither did the raw variables with the exception of vertical velocity. Given the noise and uncertainties present in all the data sets used in the research and the likely possibility of non-linear interactions occurring, this null result is not unexpected. To better quantify the relationship between aerosol concentrations and rainrate in the future, additional coincident observations of these parameters with an important focus being the relative vertical distributions of aerosols and clouds are needed. Fortunately, the recent advent of CALIPSO and CloudSat data open up this possibility for future research.
Acknowledgements. This research is supported by NASA's Radiation sciences, Interdisciplinary sciences, an EOS grant, and ACMAP programs. The CERES SSF data that contains the merged MODIS and CERES were obtained through the NASA Langley Distributed Active Archive Systems. We would like to also recognize Aaron Naegar for calculating CALIPSO aerosol layer heights shown in Fig. 7.

Edited by: J. Quaas

\section{References}

Ackerman, A. S., Toon, O. B., Stevens, D. E., Heymsfield, A. J., Ramanathan, V., and Welton, E. J.: Reduction of tropical cloudiness by soot, Science, 288, 1042-1047, 2000.

Ackerman, A. S., Toon, O. B., Stevens, D. E., and Coakley Jr., J. A.: Enhancement of cloud cover and suppression of nocturnal drizzle in stratocumulus polluted by haze, Geophys. Res. Lett., 30, L1381, doi:10.1029/2002GL016634, 2003.

Albrecht, B.: Aerosols, Cloud Microphysics, and Fractional Cloudiness, Science, 245, 1227-1230, 1989.

Andreae, A., Rosenfeld, D., Artaxo, P., et al.: Smoking rain clouds over the Amazon, Science, 303, 1337-1342, 2004.

Brenguier, J.-L., Pawlowska, H., and Schuller, L.: Cloud microphysical and radiative properties for parameterization and satellite monitoring of the indirect effect of aerosol on climate, J. Geophys. Res., 108(D15), 8632, doi:10.1029/2002JD002682, 2003.

DeMott, P. J., Sassen, K., Poellot, M. R., Baumgardner, D., Rodgers, D. C., Brooks, S. D., Prenni, A. J., and Kreidenweis, S. M.: African dust aerosols as atmospheric ice nuclei, Geophys. Res. Lett., 30, 1732, doi:10.1029/2003GL017410, 2003.

Feingold, G.: Modeling of the first indirect effect: Analysis of measurement requirements, Geophys. Res. Lett., 30(6), 1997, doi:10.1029/2003GL017967, 2003.

Feingold, G., Eberhard, W. L., Veron, D. E., and Previdi, M.: First measurements of the Twomey indirect effect using ground-based remote sensors, Geophys. Res. Lett., 30(6), 1287, doi:10.1029/2003GL016633, 2003.

Han, Q. Y., Rossow, W. B., and Lacis, A. A.: Near-global survey of effective droplet radii in liquid water clouds using ISCCP data, J. Climate, 7, 465-497, 1994.

Han, Q., Rossow, W. B., Chou, J., and Welch, R. M.: Global survey of the relationships of cloud albedo and liquid water path with droplet size using ISCCP., J. Climate, 11, 1516-1528, 1998.

Hanson, J., Sato, M., and Ruedy, R.: Radiative forcing and climate response, J. Geophys. Res., 102, 6831-6864, 1997.

Iguchi, T., Kozu, T., Meneghini, R., Awaka, J., and Okamoto, K.: Rain-profiling algorithm for the TRMM precipitation radar, J. App. Meteorol., 39, 2038-2052, 2000.

Jeong, M.-J., Li, Z., Andrews, E., and Tsay, S.-C.: Effect of aerosol humidification on the column aerosol optical thickness over the Atmospheric Radiation Measurement Southern Great Plains site, J. Geophys. Res., 112, D10202, doi:10.1029/2006JD007176, 2007.

Johnson, B. T., Shine, K. P., and Forster, P. M.: The semi-direct aerosol effect: Impact of absorbing aerosols on marine stratocumulus, Q. J. Roy. Meteorol. Soc., 130, 1407-1422, 2004.

Jones, T. A., McGrath, K. M., and Snow, J. T.: Association Between NSSL Mesocyclone Detection Algorithm detected vortices and 
tornadoes, Wea. Forecasting, 19, 872-890, 2004.

Jones, T. A. and Christopher, S. A.: Seasonal variation in satellite derived effects of aerosols on clouds in the Arabian Sea, J. Geophys. Res., 113, D09207, doi:10.1029/2007JD009118, 2008.

Kalnay, E., Kanamitus, M., Kitsler, R., et al.: The NCEP/NCAR 40-year reanalysis project, B. Am. Meteorol. Soc., 77, 437-471, 1996.

Kaufman, Y. J. and Fraser, R. S.: The effect of smoke particles on clouds and climate forcing, Science, 277, 1636-1639, 1997.

Kaufman, Y. J., Koren, I., Remer, L. A., Rosenfeld, D., and Rudich, Y.: The effect of smoke, dust, and pollution, aerosol on shallow cloud development over the Atlantic Ocean, Proc. Natl. Acad. Sci., 102(32), 11207-11212, 2005a.

Khain, A. P., Rosenfeld, D., and Pokrovsky, A.: Aerosol impact on the dynamics and microphysics of convective clouds, Q. J. Roy. Meteorol. Soc., 131, 2639-2663, 2005.

Koren, I., Kaufman, Y. J., Remer, L. A., Rosenfeld, D., and Rudich, Y.: Aerosol invigoration and restructuring of Atlantic convective clouds, Geophys. Res. Lett., 32(14), L14828, doi:10.1029/2005GL023187, 2005.

Koren, I., Remer, L. A., Kaufman, Y. J., Rudich, Y., and Martins, J. V.: On the twilight zone between clouds and aerosols, Geophys. Res. Lett., 34, L08805, doi:10.1029/2007GL029253, 2007.

Koren, I., Martins, J. V., Remer, L. A., and Afargan, H.: Smoke invigoration versus inhibition of clouds over the Amazon, Science, 321, 946-949, 2008.

Kummerow C., Simpson, J., Thiele, O., et al.: The status of the Tropical Rainfall Measuring Mission (TRMM) after two years in orbit, J. Appl. Meteorol., 39, 1965-1982, 2000.

Lin, J. C., Matsui, T., Pielke Sr., R. A., and Kummerow, C.: Effects of biomass burning derived aerosols on precipitation and clouds in the Amazon Basin: a satellite-based empirical study, J. Geophys. Res., 111, D19204, doi:10.1029/2005JD006884, 2006.

Loeb, N. G. and Manalo-Smith, N.: Top-of-atmosphere direct radiative effect of aerosols over global oceans from merged CERES and MODIS observations, J. Climate, 18, 3506-3526, 2005.

Lohmann, U. and Feichter, J.: Global indirect aerosol effects: a review, Atmos. Chem. Phys., 5, 715-737, 2005, http://www.atmos-chem-phys.net/5/715/2005/.

Lohmann, U. and Lesins, G.: Comparing continental and oceanic cloud susceptibilities to aerosols, Geophys. Res. Lett., 30(15), 1791, doi:10.1029/2003GL017828, 2003.

Mauger, G. S. and Norris, J. R.: Meteorological bias in satellite estimates of aerosol-cloud relationships, Geophys. Res. Lett., 34, L16824, doi:10.1029/2007GL029952, 2007.

Marshak, A., Wen, G., Coakley, J. A., Remer, L. A., Loeb, N. G., and Cahalan, R. F.: A simple model for the cloud adjacency effect and the apparent bluing of aerosols near clouds, J. Geophys. Res., 113, D14S17, doi:10.1029/2007JD009196, 2008.

Martins, J. A., Silva Dias, M. A. F., Gonçalves, F. L. T.: Impact of biomass burning aerosols on precipitation in the Amazon: A modeling case study, J. Geophys. Res., 114, D02207, doi:10.1029/2007JD009587, 2009.

Matsui, T., Masunaga, H., Kreidenweis, S. M., Pielke Sr., R. A., Tao, W.-K., Chin, M., and Kaufman, Y. J.: Satellite based assessment of marine low cloud variability associated with aerosol, atmospheric stability, and the diurnal cycle, J. Geophys. Res., 111, D17204, doi:10.1029/2005JD006097, 2006.

Minnis, P., Young, D. F., Sun-Mack, S., Heck, P. W., Doelling, D.
R., and Trepte, Q.: CERES Cloud Property Retrievals from Imagers on TRMM, Terra, and Aqua., Proc. SPIE 10th International Symposium on Remote Sensing: Conference on Remote Sensing of Clouds and the Atmosphere VII, Barcelona, Spain, 8-12 September, 37-48, 2003.

Morisette, J. T., Giglio, L., Csiszar, I., Setzer, A., Schroeder, W., Morton, D., and Justice, C. O.: Validation of MODIS active fire detection products derived from two algorithms, Earth Interactions, 9, 1-23, 2005.

Nakajima, T., King, M. D., and Spinhirne, J. D.: Determination of the optical thickness and effective particle radius of clouds from reflected solar radiation measurements. Part II: Marine stratocumulus observations, J. Atmos. Sci., 48, 728-750, 1991.

Nicholson, S. E., Some, B., McCollum, J., et al.: Validation of TRMM and other rainfall estimates with a high-density gauge dataset for West Africa. Part II: Validation of TRMM rainfall products, J. Appl. Meteorol., 42, 1355-1368, 2003.

Peng, Y., Lohmann, U., Leaitch, R., Banic, C., and Couture, M.: The cloud albedo-cloud droplet effective radius relationship for clean and polluted clouds from RACE and FIRE.ACE, J. Geophys. Res., 107(D11), 4106, doi:10.1029/2000JD000281, 2002.

Penner, J. E., Dong, X., and Chen, Y.: Observational evidence of a change in radiative forcing due to the indirect aerosol effect, Nature, 427, 231-234, 2004.

Platnick, S., King, M. D., Ackerman, S. A., Menzel, W. P., Baum, B. A., Riédi, J. C., and Frey, R. A.: The MODIS Cloud Products: Algorithms and Examples from Terra, IEEE Trans. Geosci. Rem. Sens., 41, 459-473, 2003.

Quaas, J., Boucher, O., and Breon, F.-M.: Aerosol indirect effects in POLDER satellite data and the Laboratoire de Meteorologie Dynamique-Zoom (LMDZ) general circulation model, J. Geophys. Res., 109, D08205, doi:10.1029/2003JD004317, 2004.

Quaas, J., Boucher, O., Bellouin, N., and Kinne, S.: Satellite-based estimate of the direct and indirect aerosol climate forcing, J. Geophys. Res., 113, D05204, doi:10.1029/2007JD008962, 2008.

Ramana, M. V. and Ramanathan, V.: Abrupt transition from natural to anthropogenic aerosol radiative forcing: Observations at the ABC-Maldives Climate Observatory, J. Geophys. Res., 111, D20207, doi:10.1029/2006JD007063, 2006.

Ramanathan, V., Crutzen, P. J., Kiehl, J. T., and Rosenfeld, D.: Aerosols, climate, and the hydrological cycle, Science, 294, 2119-2124, 2001.

Reid, J. S., Hobbs, P. V., Ferek, R. J., Blake, D. R., Martins, J. V., Dunlap, M. R., and Liousse, C.: Physical, chemical, and optical properties of regional hazes dominated by smoke in Brazil, J. Geophys. Res., 103, 32059-32080, 1998.

Reid, J. S., Hobbs, P. V., Rangno, A. L., and Hegg, D. A.: Relationships between cloud droplet effective radius, liquid water content, and droplet concentration for warm clouds in Brazil embedded in biomass smoke, J. Geophys. Res., 104(D6), 6145-6153, 1999.

Redemann, J., Zhang, Q., Livingston, J., Russell, P., Shinozuka, Y., Clarke, A., Johnson, R., and Levy, R.: Testing aerosol properties in MODIS Collection 4 and 5 using airborne sunphotometer observations in INTEX-B/MILAGRO, Atmos. Chem. Phys., 9, 8159-8172, 2009, http://www.atmos-chem-phys.net/9/8159/2009/.

Remer, L. A. and Kaufman, Y. J.: Aerosol direct radiative effect at the top of the atmosphere over cloud free ocean derived from four 
years of MODIS data, Atmos. Chem. Phys., 6, 237-253, 2006, http://www.atmos-chem-phys.net/6/237/2006/.

Richman, M. B. and Gong, X.: Relationships between the definition of the hyperplane width to the fidelity of principal component loading patterns, J. Climate, 12, 1557-1576, 1999.

Rosenfeld, D., Kaufman, Y. J., and Koren, I.: Switching cloud cover and dynamical regimes from open to closed Benard cells in response to the suppression of precipitation by aerosols, Atmos. Chem. Phys., 6, 2503-2511, 2006,

http://www.atmos-chem-phys.net/6/2503/2006/.

Rosenfeld, D., Lohmann, U., Raga, G. B., O’Dowd, C. D., Kulmala, M., Fuzzi, S., Reissell, A., and Andreae, M. O.: Flood or drought: How do aerosols affect precipitation, Science, 321, 1309-1313, 2008.

Schwartz, S. E., Harshvardhan, and Benkovitz, C. M.: Influence of anthropogenic aerosol on cloud optical depth and albedo shown by satellite measurements and chemical transport modeling, Proc. Nat. Acad. Sci. US, 99, 1784-1789, 2002.

Teller, A. and Levin, Z.: The effects of aerosols on precipitation and dimensions of subtropical clouds: a sensitivity study using a numerical cloud model, Atmos. Chem. Phys., 6, 67-80, 2006, http://www.atmos-chem-phys.net/6/67/2006/.

Turner, D. D., Vogelmann, A. M., and Austin, R. T.: Thin Liquid Water Clouds: Their Importance and Our Challenge, B. Am Meteorol. Soc, 88(2), 177-190, doi:10.1175/BAMS-88-2-177, 2007.
Twomey, S. A.: The influence of pollution on the shortwave albedo of clouds, J. Atmos. Sci., 34, 1149-1152, 1977.

Vaughan, M., Young, S., Winker, D., Powell, K., Omar, A., Liu, Z., Hu, Y., and Hostetler, C.: Fully automated analysis of spacebased lidar data: an overview of the CALIPSO retrieval algorithms and data products, Proc. SPIE, 5575, pp. 16-30, 2004.

Wen, G., Marshak, A., and Cahalan, R. F.: Impact of 3D Clouds on Clear Sky Reflectance and Aerosol Retrieval in a Biomass Burning Region of Brazil, IEEE Geo. Rem. Sens. Lett., 3, 169172, 2006.

Williams, E., Rosenfeld, D., Madden, N., et al.: Contrasting convective regimes over the Amazon: Implications for cloud electrification, J. Geophys. Res., 107, 8082, doi:10.1029/2001JD000380, 2002.

Yuan, T., Li, Z., Chang, F. L., Vant-Hull, B., and Rosenfeld, D.: Increase of cloud droplet size with aerosol optical depth: An observation and modeling study, J. Geophys. Res., 113, D04201, doi:10.1029/2007JD008632, 2008.

Zhang, J. and Reid, J. S.: MODIS aerosol product analysis for data assimilation: Assessment of over-ocean level 2 aerosol optical thickness retrievals, J. Geophys. Res., 111, D22207, doi:10.1029/2005JD006898, 2006. 